\title{
Bioequivalence of Two Oral Dimethyl Fumarate Extended Release Capsules in Healthy Subjects: A Randomized, Open Label, Single-Dose, 2-Way Crossover Study
}

\author{
Maligne $\mathrm{GE}^{1^{*}}$, Feleder $\mathrm{EC}^{2}$, Yerino $\mathrm{GA}^{2}$, Otero $\mathrm{AM}^{2}$ and Roldán EJA \\ ${ }^{1}$ Clinical Research Managment, Buenos Aires, Argentina \\ ${ }^{2}$ F.P. Clinical Pharma-Pharmacokinetic Unit, Buenos Aires, Argentina \\ ${ }^{3}$ Gador S.A., Buenos Aires, Argentina
}

\begin{abstract}
The hypothesis for the design of this project was that the extended release formulation containing dimethyl fumarate $240 \mathrm{mg}$ DIMEFUL $\AA$, developed by Gador will present similar bioavailability with respect to the reference formulation, TECFIDERA $\otimes$ by Biogen Idec, measured in terms of speed and absorption. A clinical study of singledose bioequivalence (in 2 stages) was designed to be carried out in healthy subjects. This study was opened of two periods, two sequences, crossed, randomized under fasting conditions. Eight out of ten subjects involved in this pilot study (stage 1) were randomized and completed the 2 periods of administration of the treatments. Data of all the subjects who completed the 2 periods of treatment administration were used for pharmacokinetic purposes. The design of the study was adequate to determine the bioequivalence of the Test and Reference Products. The 7- day washout period was sufficient to allow the complete elimination of the formulations before the next dosing period.

Conclusion: In relation to monomethyl fumarate; The extended release formulation containing dimethyl fumarate $240 \mathrm{mg}$, developed by Gador, DIMEFUL $®$, presents similar bioavailability, measured in terms of speed and extension of absorption in relation to the reference formulation, TECFIDERA® by Biogen Idec. Intrasubject CVs were on the order of $30 \%$ to $40 \%$ for the 3 pharmacokinetic parameters; indicating that the molecule and/or the formulation shows high variability in absorption and must be considered for the calculation of sample size of Stage 2. This improved process will serve for clinical assessment in patients. Individual plasma concentrations showed results lower than the lower limit of quantification of the validated analytical method. It is suggested to adjust the method by lowering said level for Stage 2. It is possible to consider extending the range of Bioequivalence for Cmax to $70-143 \%$ in Stage 2; since the intrasubject CV was $>30 \%$ and the Reference geometric mean is between $0.80-1.25$ in Stage 1.
\end{abstract}

Keywords: Bioequivalence; Plasma pharmacokinetic; Body mass index

\section{Introduction}

Dimethyl fumarate (DMF), the methyl ester of fumaric acid, is a compound used years ago to treat psoriasis with both, oral and topic formulations. Due to severe gastric side effects the oral formulations were discouraged and finally disrupted from the market. Afterwards, the drug was repositioned to treat multiple sclerosis (MS) using a modified release formulation, having the advantage of avoiding the gastric phase. MS is a disease characterized by the presence of demyelinating central nervous system degenerative lesions. Although there are some genes associated to MS at the human chromosome 6, there others also linked, and the conditions seems to be in great part driven by environmental factors and other epigenetics factors [1]. Therefore, autoimmune, inflammatory and oxidative mechanisms, are involved in the pathologic process. The prevalence has been assessed in some regions and it is estimated that 1 in 1,000 people, mostly women, is affected. Nevertheless, the prevalence varies in different regions and the condition shares many of the features of a rare disease. About $10 \%$ of patients die as a result of MS or its complications, others remain during a long process with disabilities and serve deterioration of their quality of life [2]. There is no cure for MS, but some medications can ameliorate the symptoms and/or prolong the time free of relapses [3]. With such aim DMF was shown to significantly expand on relapse rate and time to progression, improving quality of life. MS treatment with DMF is off-patent, with exception of the use of DMF extended release formulations which have been recognized as inventive in some countries but not in many others. MS treatment requires safe, highquality formulations $[4,5]$. The use of, low-quality, DMF formulations can cause, disease exacerbations and side effects [6-11]. Hence, regulatory authorities are facing significant challenges when defining appropriate requirements for follow-on drugs that show high degree of similarity to standard treatments [3,4], extended-release capsules Bioequivalence of Dimethyl fumarate formulation is an essential attribute of a medicine with respect to a reference, where both have different origins of manufacture, contain the same active ingredient and quantity and are similar in amount and speed of absorbed drug, when administered orally, within limits reasonable. The generic medications contribute to moderate prices and make the product more accessible to patients. But they are pharmaceutical equivalents with the innovator trademark in terms of the active substance, and may differ in other components such as flavourings, stabilizers, and other excipients, in addition to the process of manufacture and in the manufacturer's own laboratory. As DMF is metabolized in the intestinal lumen to monomethyl fumarate (MMF) and may interact locally, at the intestinal walls and systemically, it is very important to secure the similarity of the active components release and absorption. In the present study we

*Corresponding author: Guillermo Maligne, Clinical Research Managment, Buenos Aires, C1414CUI, Argentina, Tel: (+54) 911 68993590; E-mail: gmaligne@gador.com.ar

Received May 18, 2018; Accepted June 17, 2018; Published June 27, 2018

Citation: Maligne GE, Feleder EC, Yerino GA, Otero AM, Roldán EJA (2018) Bioequivalence of Two Oral Dimethyl Fumarate Extended Release Capsules in Healthy Subjects: A Randomized, Open Label, Single-Dose, 2-Way Crossover Study. J Bioequiv Availab 10: 58-74. 378. doi: 10.4172/0975-0851.1000380

Copyright: (C) 2018 Maligne GE, et al. This is an open-access article distributed under the terms of the Creative Commons Attribution License, which permits unrestricted use, distribution, and reproduction in any medium, provided the original author and source are credited. 
Citation: Maligne GE, Feleder EC, Yerino GA, Otero AM, Roldán EJA (2018) Bioequivalence of Two Oral Dimethyl Fumarate Extended Release Capsules in Healthy Subjects: A Randomized, Open Label, Single-Dose, 2-Way Crossover Study. J Bioequiv Availab 10: 58-74. 378. doi: 10.4172/0975-0851.1000380

show for the first time in Latin America that the speed and amount absorbed of the active metabolite MMF after administering a single dose of $240 \mathrm{mg}$ of DMF of the test product-Dimeful' (Gador S.A., Buenos Aires), extended-release capsules did not present statistically significant differences with respect to the administration of a single dose of $240 \mathrm{mg}$ of DMF of the reference product -Tecfidera (Biogen Idec, Cambridge), extended-release capsules, in healthy volunteer subjects. It is also important to highlight that we developed a new method to measure the concentration of MMF in patients and the determination of the PK parameters, which in turn can further assess the low concentrations expected in MS patients. These results indicate the equivalent clinical efficacy, safety and tolerance of the tested drug.

\section{Subjects and Methods}

\section{Study design and setting}

This trial was an open label, single-dose, randomized-sequence, two-treatment, two-period, single-center, balanced, crossover study. It was carried out at FP Clinical Pharma Pharmacokinetic Unit, Buenos Aires, Argentina, between May 2016 and August 2016 (Figure 1A and B summarizes the study design). The study was performed in two sequential phases due to the high variability of MMF pharmacokinetic (PK) parameters reported in literature both in healthy subjects and patients with MS [12]. The first phase of the study was conducted essentially to determine the Cmax intra-individual coefficient of variation (CV) for MMF of the study population. The second phase of the study was conducted to complete the required number of subjects according to the PK results obtained in the first phase. The study protocol and the Informed Consent Form (IFC) were both approved by the Institutional Review Board, the Independent Ethic Committee (Comité de Ética en Investigación Clínica "CEIC", Buenos Aires, Argentina, revision number 1262/71/2015) and the local Regulatory Agency (ANMAT-MOH. Argentina) before the beginning of the study. An approved IFC was obtained from all subjects who volunteered to participate in the study. All clinical procedures were conducted in concordance with the Ethical Principles for Medical Research Involving Human Subjects listed in the latest version of the Declaration of Helsinki, according to the ICH-Good Clinical Practice guidance, and to the FDA guidance for conducting bioavailability and bioequivalence studies for oral administered drugs [13-15].

\section{Interventions}

The study subjects were randomly assigned, each group of 4 in the first phase and each group of 9 in the second phase, to receive a single dose of dimethyl fumarate each in one of two sequences of treatments (Test-Reference or Reference-Test) in compliance with the FDA specific guidance [16]. Dimethyl fumarate was administered either in one $240 \mathrm{mg}$ extended-released capsules of Dimeful as test preparation (batch No. 25162), manufactured by Gador S.A. Laboratory (Buenos Aires, Argentina), or in one $240 \mathrm{mg}$ extendedreleased capsules of the innovator product Tecfidera (batch No. CANEELSB00), manufactured by Biogen Idec. (Cambridge, MA 02142 , USA) as reference preparation which was purchased abroad. Oral administration of treatments included $240 \mathrm{ml}$ of non-carbonated mineral water after an overnight fast of at least 10 hours in two different dosing periods according to the predetermined randomized sequence of treatment. A 7-day wash-out period between treatments was established regarding the FDA guidance recommendation for long half-life drug studies such as MMF [16].

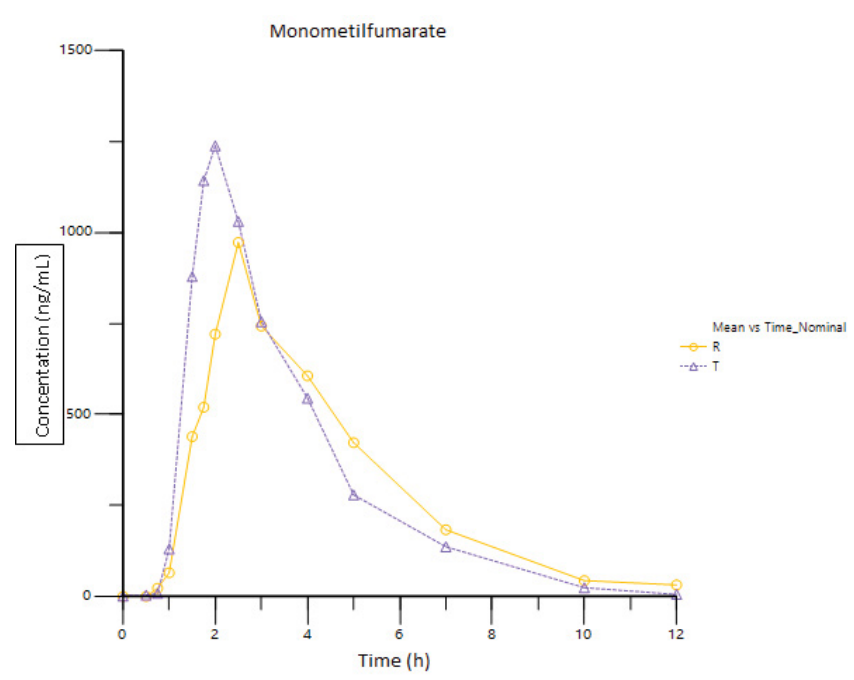

Figure 1A: Summary of results and conclusions. Summary of pharmacokinetic results: Mean -time concentration curves for each treatment $(n=26)$ - arithmetic scale $\mathrm{R}=$ reference product $/ \mathrm{t}=$ test product

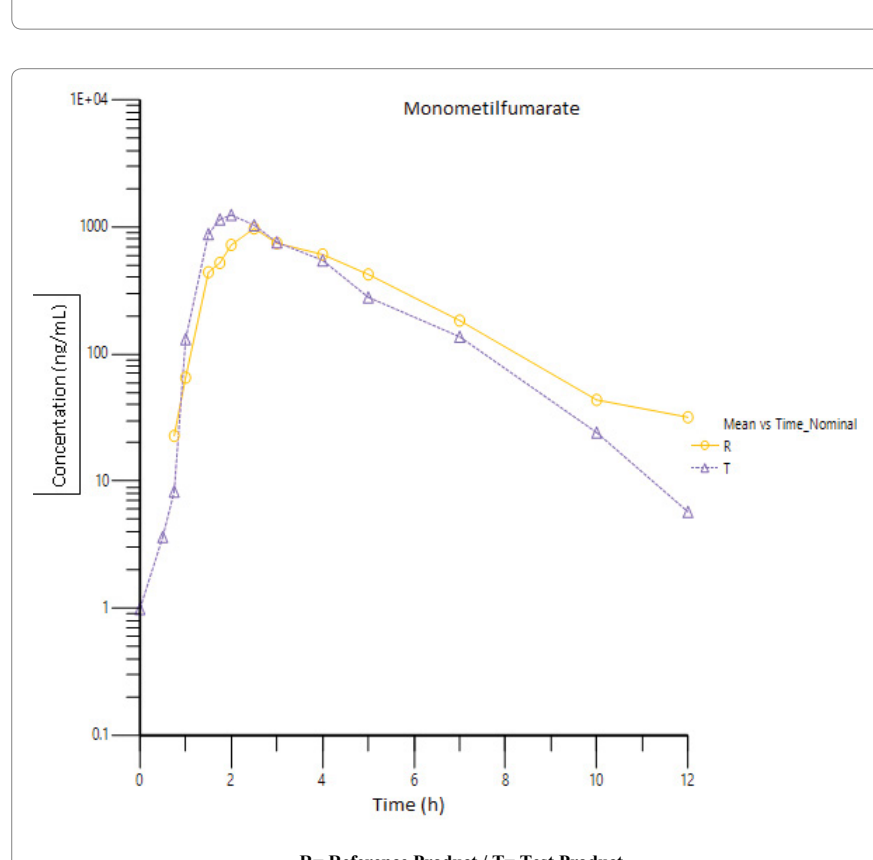

Figure 1B: Mean - time concentration curves for each treatment $(n=26)-S e m i$ logarithmic scale.

Subjects were required to abstain from water consumption between one-hour pre-dosing and until $2 \mathrm{~h}$ after dosing, and also, they were not allowed to crush or chew the study medication. Mouth checks were performed after each drug administration. Then, subjects remained under fasting condition until after the 4-h pharmacokinetic blood sample time point. A standard lunch and afternoon meal were administered after the $4^{\text {th }}$ and $8^{\text {th }}$ hour of drug administration. The study medication was storage during the whole study in concordance with the environmental conditions established by the prescribing information of the product provided by the sponsor. 
Citation: Maligne GE, Feleder EC, Yerino GA, Otero AM, Roldán EJA (2018) Bioequivalence of Two Oral Dimethyl Fumarate Extended Release Capsules in Healthy Subjects: A Randomized, Open Label, Single-Dose, 2-Way Crossover Study. J Bioequiv Availab 10: 58-74. 378. doi: 10.4172/0975-0851.1000380

\section{Study population}

Sample size was calculated using the formula developed by Marzo and Balant, considering $\mathrm{C}_{\max }$ intra-individual coefficient of variation (CV) $>30 \%$ for MMF obtained in the first phase of the study [17]. A total of 31 healthy male and female adult subjects nonsmokers (nonpregnant and non-breastfeeding females) between 21 and 55 years of age were enrolled. Inclusion criteria included Body Mass Index (BMI) ranging from 19 to $27 \mathrm{~kg} / \mathrm{m}^{2}$. Female subjects of childbearing potential (i.e. not surgically sterile or at least 2 years postmenopausal or menopause confirmed by follicle-stimulating hormone [FSH]) testing were required to have a negative pregnancy test at screening. Also, they were required to agree to use a highly effective contraception method while on study treatment and during a period of 7 days after the last dose of the study drugs. Vital signs (heart rate, systolic and diastolic blood pressure, and axillary temperature), laboratory tests (hematology, biochemistry, blood clots, and urinalysis) and 12-lead ECGs had to be within normal range. Negative test for VIH, hepatitis B and C viruses were also required to enter into the study. Subjects with a history or current manifestations of gastrointestinal disease or surgery, or cardiovascular, respiratory, hepatic, renal, hematopoietic, endocrinemetabolic, neurological or psychiatric diseases were excluded. Subjects who reported a history of alcohol or drug abuse in the last year, and with documented evidence of pre-existing lymphocyte count values below the normal reference ranges in the last 6 to 12 months were also excluded. Also, volunteers were restricted to use of medicine of any kind, including herbal medicines within the previous two weeks and throughout the study execution. Other standard exclusion criteria for $\mathrm{BD} / \mathrm{BE}$ studies were adopted for subject enrollment [15]. Subjects were required to abstain from foods and beverages intake with xanthine's or alcohol and to avoid sun exposure, strenuous exercise and sports during $24 \mathrm{~h}$ before the administration of the research product and during the hospitalizations at the pharmacokinetic Unit.

\section{Sample collection}

Serial blood samples for pharmacokinetic assessments were collected by venipuncture over a 12 -hour period at the following points: 0 (pre-dose), $0.5,0.75,1,1.5,1.75,2,2.5,3,4,5,7,10$, and 12 hours after oral administration of each treatment. For each sample, approximately $8 \mathrm{ml}$ of blood was collected into vacutainers containing EDTA as an anticoagulant. Blood samples were immediately centrifuged at 3,500 rpm over 10 minutes and the separated plasma was frozen at $-20^{\circ} \mathrm{C}$ before analysis.

\section{Bioanalytic procedures}

Since DMF concentrations are non-quantifiable using HPLC/ fluorescence (FLD) or UV method, MMF concentrations, the active metabolite of DMF in human plasma were determined by HPLC/ fluorescence (FLD) method using a liquid chromatograph SHIMADZU Prominence 20 with an automatic injector SIL-30AC and FLD RF-20A XS detector with an analytical column $25 \times 0.46 \mathrm{~cm}$, Hypersil BDS, $\mathrm{C} 18,5 \mu$, fluorescence detection within 360 to $432 \mathrm{~nm}$. Quantification of MMF was performed using an internal standard method. The lowest limit of quantification (LLOQ) corresponding to MMF was 0,0242 $\mu \mathrm{g} / \mathrm{l}$. The calibration curve covering the range of 0.10 to $6.70 \mu \mathrm{g} / \mathrm{l}$ was constructed. The calibration curves were linear over the calibration concentration range for each mobile phase. The precision and accuracy of the assay validation was evaluated using 2 separate analytical runs, each containing 6 quality control (QC) levels that covered the calibration range. Inter-and intra assay precision had a coefficients of variations $(\mathrm{CVs})<15 \%$ and $<20 \%$ at the LLOQ. Inter -and intra assay accuracy had mean BIAS values within $\pm 15 \%$ of nominal values and within $\pm 20 \%$ at the LLOQ. Full methodological validation was carried out according to FDA guidance for bioanalytical method validation [18].

\section{Pharmacokinetic evaluation}

The plasma concentration-time data after oral administration of a single dose of test and reference treatment were analyzed using a non-compartmental pharmacokinetic model (WinNonlin, version 6.4; Certara, US). The maximum plasma concentration and the corresponding sampling time were defined as $\mathrm{C}_{\max }$ and $\mathrm{T}_{\max }$, respectively. The elimination half-life $\left(\mathrm{T}^{1} / 2\right)$ was estimated as $\ln 2 / \lambda$. The slope of the log-linear regression function $(\lambda)$ was the first order rate constant associated with the terminal portion of the curve estimated by linear regression of time vs. log-concentration. The area under the plasma concentration-time curve from the time of dosing to the last measurable concentration (AUC0-last) was calculated using the trapezoidal rule. The AUC from dosing time extrapolated to infinity based on the last observed concentration was defined as AUCinf. which was calculated by the equation AUC0-inf $=\mathrm{AUC}+(\mathrm{Cn} / \lambda)$ where $\mathrm{Cn}$ is the last measurable concentration and $\lambda$ is the slope of the log-linear regression function. A pharmacokinetic (PK) rule was generated to treat data coming from samples presenting values less than the lower level of quantification in bioanalytical assays. Subjects who experienced twice emesis at or before the median time to maximum concentration $\left(\mathrm{T}_{\max }\right.$ for the analyte were excluded from the PK analysis set [15].

\section{Safety assessment}

Physical examination, hematology, serum chemistry (fasting glucose, urea, creatinine, liver function panel, blood clots tests), urinalyses, were performed at the screening visit (Day-21 to -1) for safety purposes. A 12-lead ECG also was carried out at screening visit. Urine pregnancy test was performed at screening visit and previous to each dosing period for female with childbearing potential. An abbreviated physical examination before drug administration was also performed in the morning. Vital signs measurements (heart rate, systolic and diastolic blood pressure in supine position and axillary temperature) were recorded at the screening visit. The same vital parameters were also determined before drug administration and at time-points 2, 4, 10 , and $12 \mathrm{~h}$ after drug administration in each dosing period. Adverse events were identified by asking the subjects general health-related questions before the dosing period and by the subject self-reporting during the study and until the follow-up visit by phone contact. The severity (eg, mild, moderate, severe), seriousness, and causality assessment of adverse events was evaluated by the investigators.

\section{Statistical analysis}

The following pharmacokinetic parameters: $\mathrm{C}_{\max }$, AUC0-last, and AUCinf were analyzed for MMF using natural log-transformed data. These PK variables were compared by means of ANOVA for a 2-treatment crossover design. The model included the fixed effects of period, sequence and treatment and the random effect of subjects within sequence. The average MMF bioavailavility of test formulation relative to the reference formulation was expressed as the ratio of respective estimated mean exposure and $90 \%$ confidence intervals (CIs) in terms of $\mathrm{C}_{\max }$, AUC0-last and AUCinf. Schuirmann's two onesided $t$ test was used to compare $\mu \mathrm{T} / \mu \mathrm{R}$ ratios for the PK parameters. In accordance with scientific standards and international guidelines for bioequivalence studies, bioequivalence was concluded if the $90 \%$ CIs for the ratio of the geometric least-squares means (test treatment/reference 
Citation: Maligne GE, Feleder EC, Yerino GA, Otero AM, Roldán EJA (2018) Bioequivalence of Two Oral Dimethyl Fumarate Extended Release Capsules in Healthy Subjects: A Randomized, Open Label, Single-Dose, 2-Way Crossover Study. J Bioequiv Availab 10: 58-74. 378. doi: 10.4172/0975-0851.1000380

treatment) was within the limits of $80 \%$ to $125 \%$ for the primary PK parameters. All statistical tests used a $5 \%$ level of significance $[15,19]$.

\section{Results}

\section{Subject population}

A total of 31 healthy Caucasian subjects were enrolled in the study. Five subjects withdrew their informed consent before the period 1 of the study due to personal reasons. Thus, a total of 26 subjects were randomized to the sequence group ( 8 subjects in the first phase and 18 subjects in the second phase). Finally, 26 subjects completed the study according to the protocol (subjects allocation and disposition is

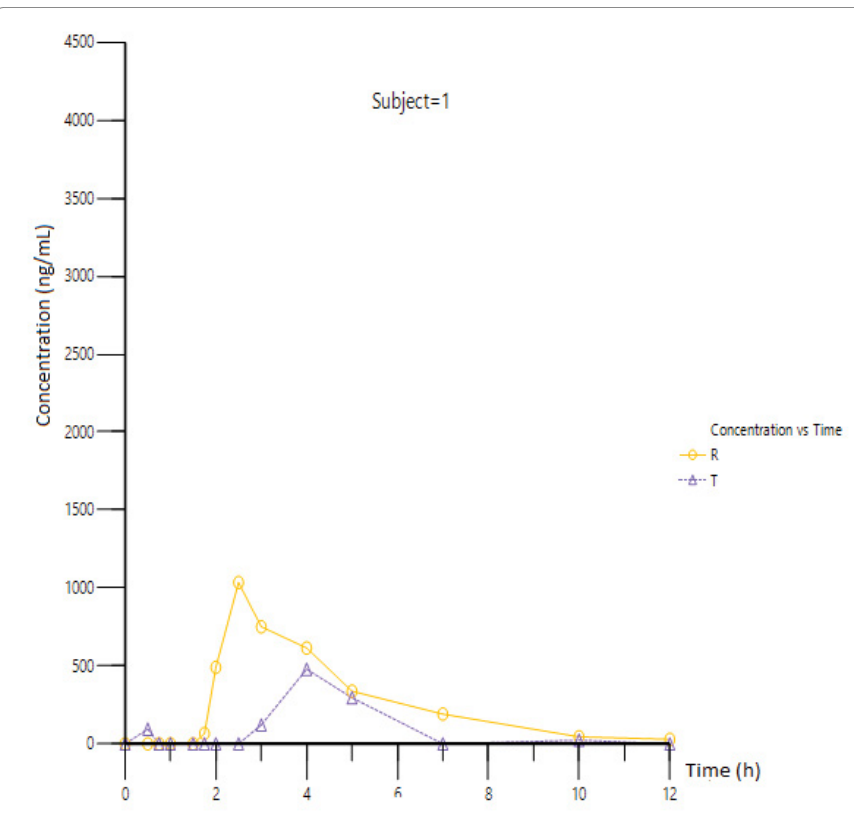

Figure 2A: Concentration curves individual-time for each treatment. Subject 1-Arithmetic Scale- R= Reference Product $/ T=$ Test Product

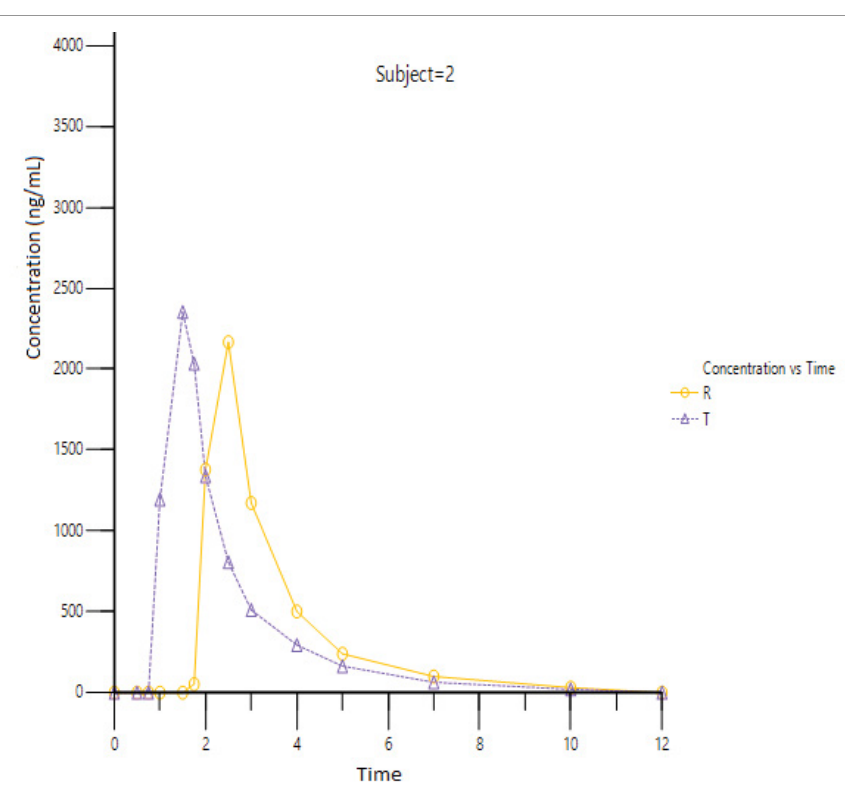

Figure 2B: Concentration curves individual-time for each treatment. Subject 2- Arithmetic Scale- $R=$ Reference Product $/ \mathrm{T}=$ Test Product summarized in Figure 2A-Z. Demographic characteristics and mean heath parameters are summarized in Table 1A-C.

\section{Pharmacokinetics}

A total of 26 subjects comprised the data set for MMF PK analysis. Figure $3 \mathrm{~A}$ and $\mathrm{B}$ shows mean plasma concentration-time curves after single dose administration of $240 \mathrm{mg}$ of test and/or reference products. The two treatment curves represented a typical profile for an extended-released formulation profile and curves were essentially similar. Plasma pharmacokinetic parameters for MMF are summarized in Table 2A-D. MMF formulations showed similar mean $\mathrm{T}_{\text {max }}$ and half-life values.

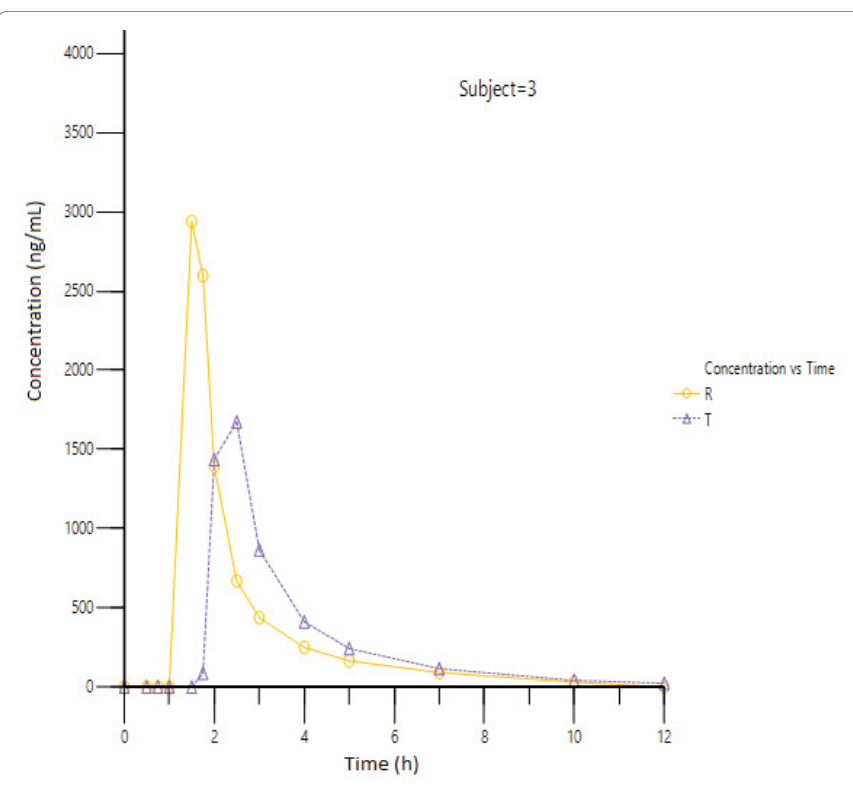

Figure 2C: Concentration curves individual-time for each treatment. Subject 3- Arithmetic Scale- R= Reference Product $/ \mathrm{T}=$ Test Product

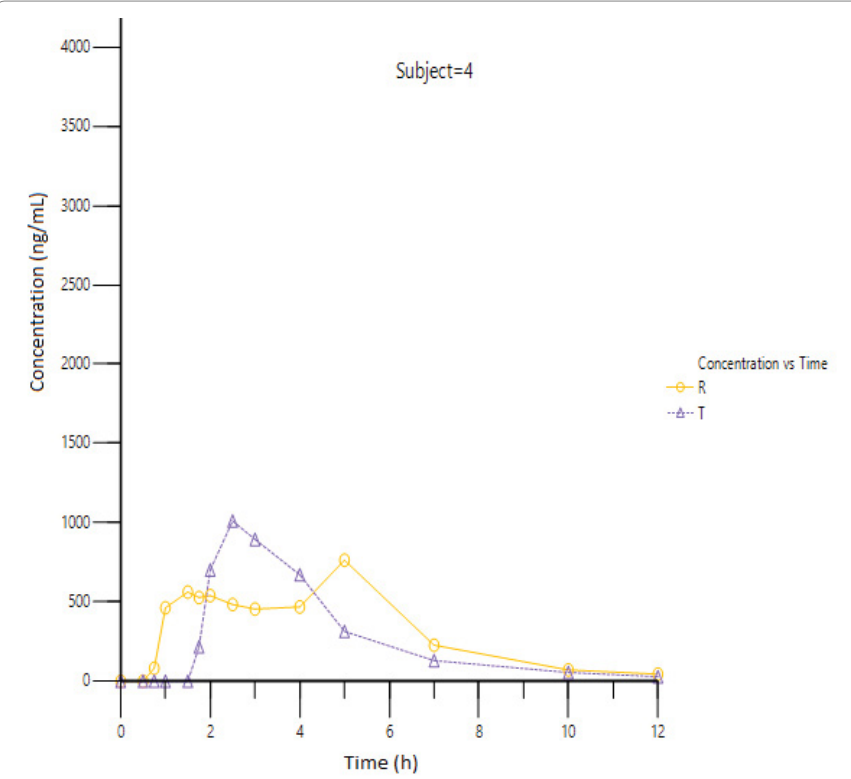

Figure 2D: Concentration curves individual-time for each treatment. Subject 4- Arithmetic Scale- R= Reference Product $/ \mathrm{T}=$ Test Product 
Citation: Maligne GE, Feleder EC, Yerino GA, Otero AM, Roldán EJA (2018) Bioequivalence of Two Oral Dimethyl Fumarate Extended Release Capsules in Healthy Subjects: A Randomized, Open Label, Single-Dose, 2-Way Crossover Study. J Bioequiv Availab 10: 58-74. 378. doi: 10.4172/0975-0851.1000380
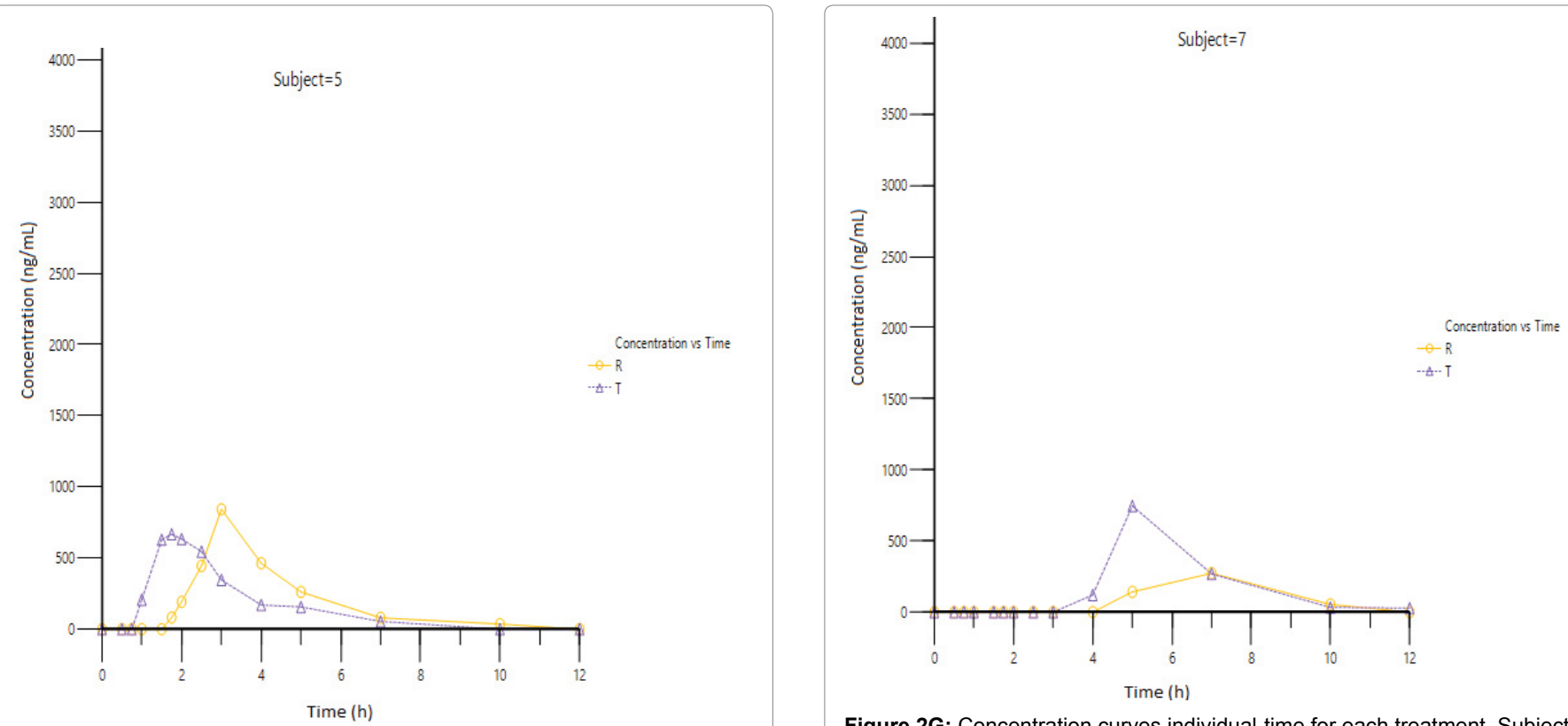

Figure 2E: Concentration curves individual-time for each treatment. Subject 5- Arithmetic Scale-R= Reference Product $/ \mathrm{T}=$ Test Product

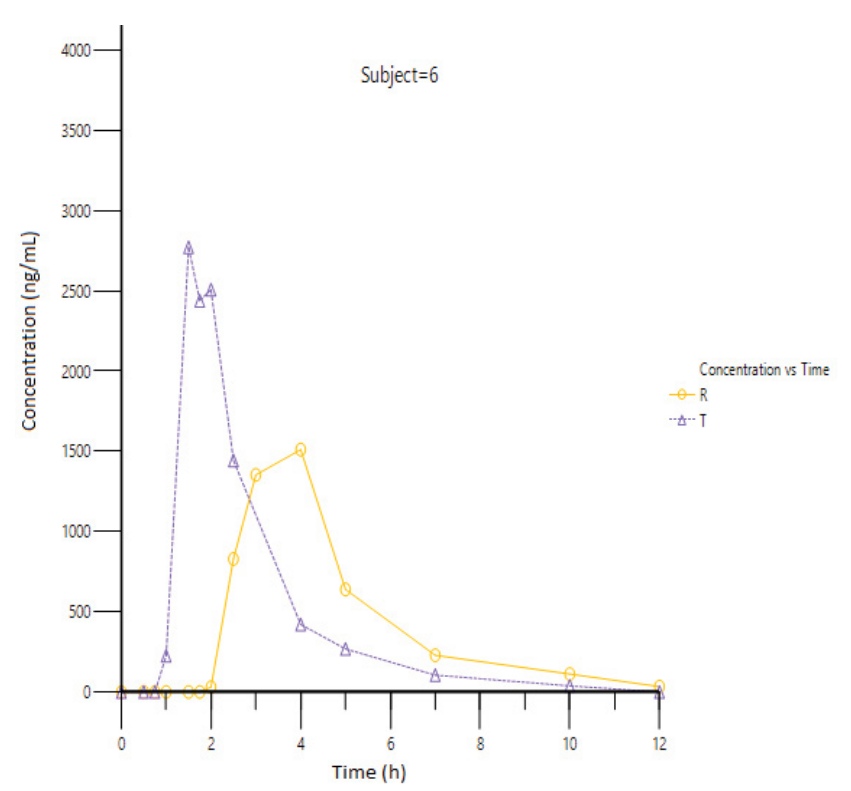

Figure 2F: Concentration curves individual-time for each treatment. Subject 6- Arithmetic Scale-R= Reference Product / T= Test Product

The analysis of variance did not show any statistically significant difference between the test and the reference formulations $(\mathrm{p}<0.05)$ in respect to the fixed effect of period, sequence, treatment and subjects within sequence as random effect for the pharmacokinetic parameters analyzed: $\ln \mathrm{C}_{\max }$, AUC0-last and AUCinf.

Statistical analysis of MMF pharmacokinetic log-transformed parameters and their geometric least squares mean ratios for the test and reference treatment are shown in Table 3. The limits of the $90 \%$ CIs for the ratios of $\mathrm{C}_{\max }$, AUC0-last, and AUCinf for their

Figure 2G: Concentration curves individual-time for each treatment. Subject 7-Arithmetic Scale-R= Reference Product $/ \mathrm{T}=$ Test Product

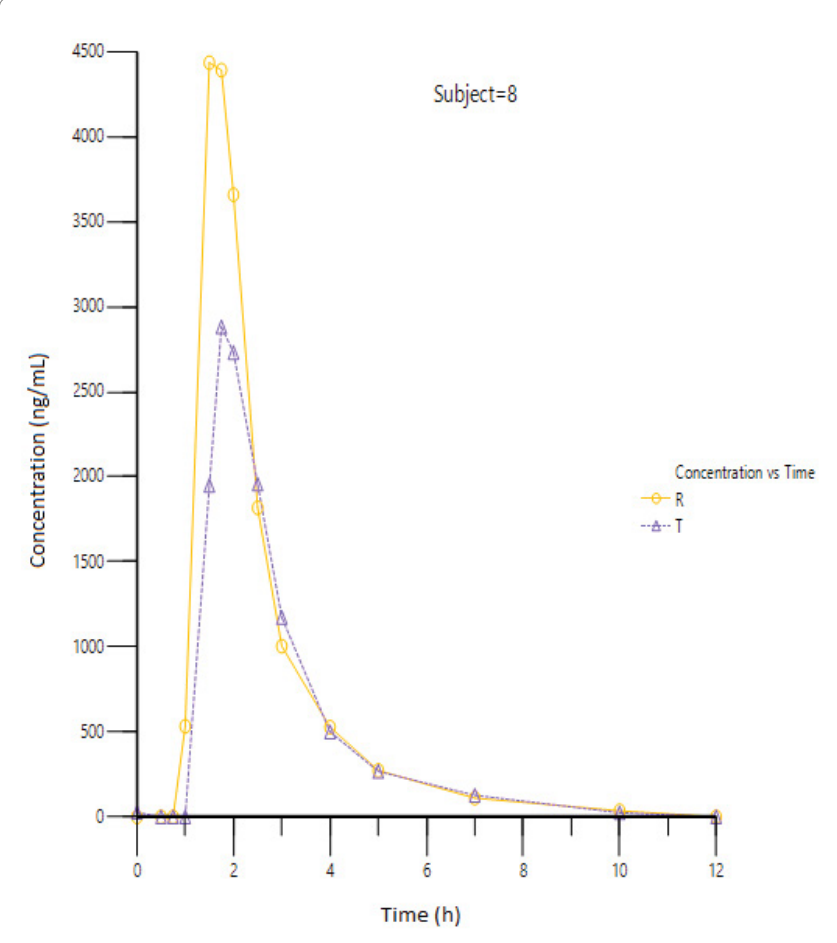

Figure 2H: Concentration curves individual-time for each treatment. Subject 8- Arithmetic Scale- R= Reference Product $/ \mathrm{T}=$ Test Product

log-transformed data fell well within 80 to $125 \%$. Coefficients of intra-individual variation for $\mathrm{C}_{\max }, \mathrm{AUC0}$-last and AUCinf $>30 \%$, $30 \%$ and $40 \%$; respectively. The null hypothesis of the two one-sided Schuirmann's $t$-test could be rejected $(\mathrm{p}<0.05)$ since Test-Reference ratio for the geometric means (\%) for all primary pharmacokinetic metrics (AUC0-t, AUCinf, $\mathrm{C}_{\max }$ ) and the corresponding two-sided $90 \%$ CIs were contained within the predefined limits of $80 \%$ to $125 \%$ (Table 4 ). 
Citation: Maligne GE, Feleder EC, Yerino GA, Otero AM, Roldán EJA (2018) Bioequivalence of Two Oral Dimethyl Fumarate Extended Release Capsules in Healthy Subjects: A Randomized, Open Label, Single-Dose, 2-Way Crossover Study. J Bioequiv Availab 10: 58-74. 378. doi: 10.4172/0975-0851.1000380

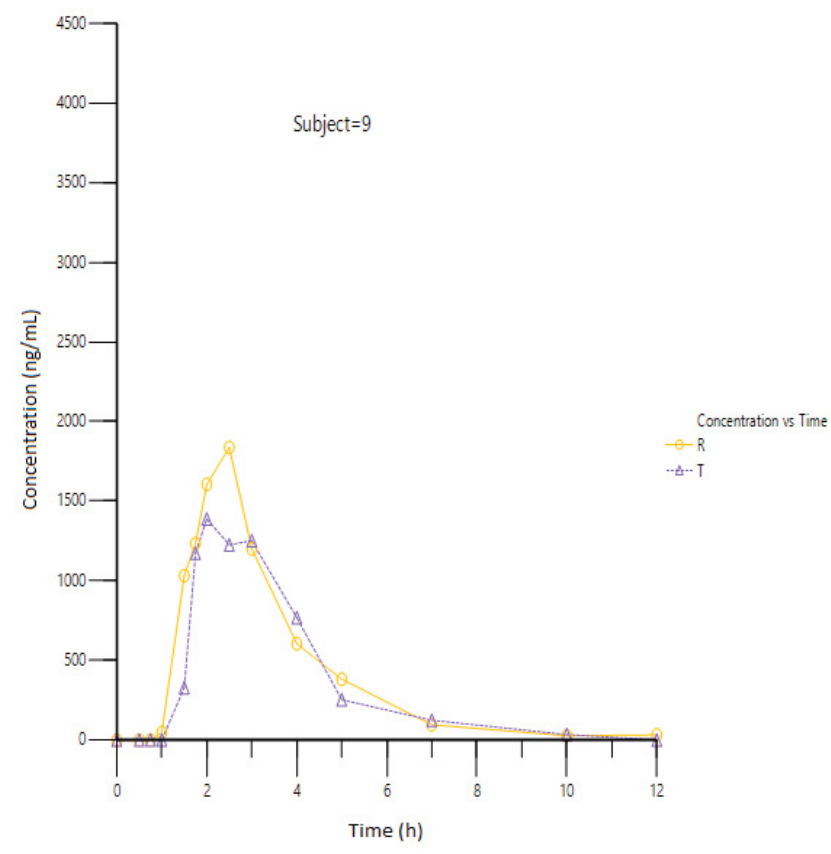

Figure 21: Concentration curves individual-time for each treatment. Subject 9- Arithmetic Scale- $R=$ Reference Product $/ T=$ Test Product

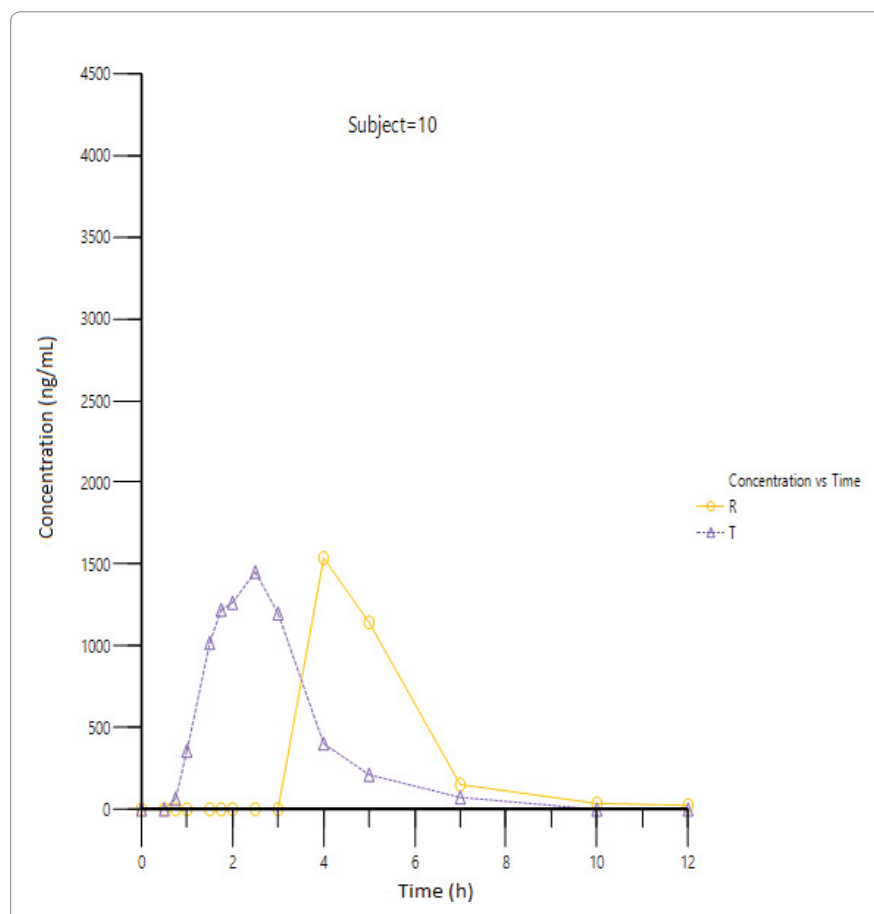

Figure 2J: Concentration curves individual-time for each treatment. Subject 10- Arithmetic Scale- $R=$ Reference Product $/ \mathrm{T}=$ Test Product

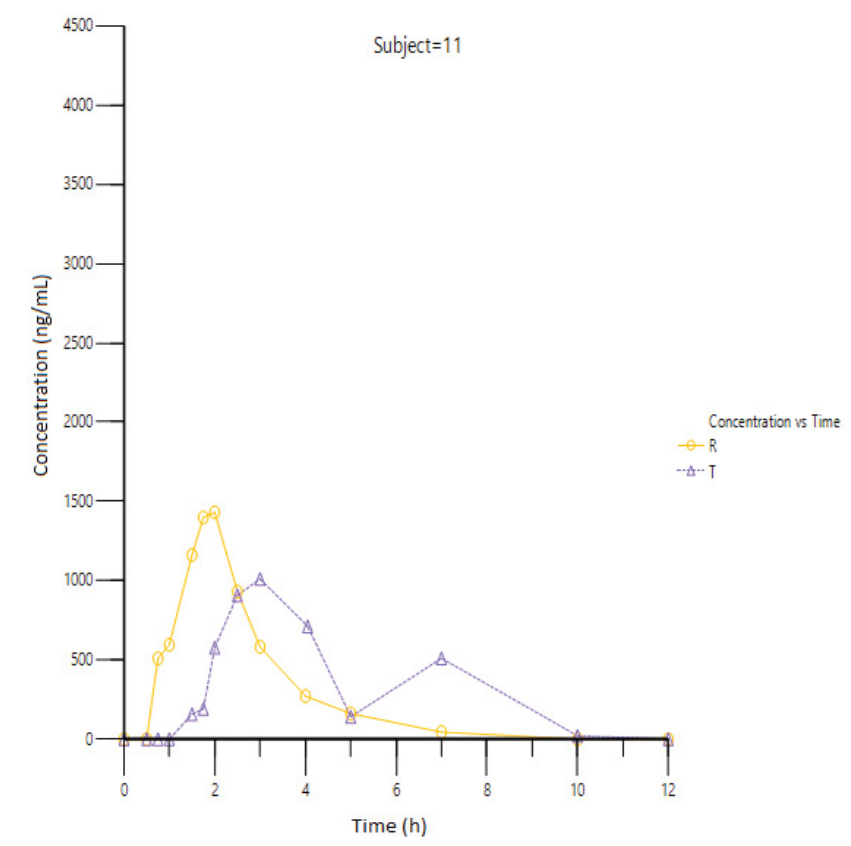

Figure 2K: Concentration curves individual-time for each treatment. Subject 11-Arithmetic Scale- $R=$ Reference Product $/ \mathrm{T}=$ Test Product

Subject $=12$

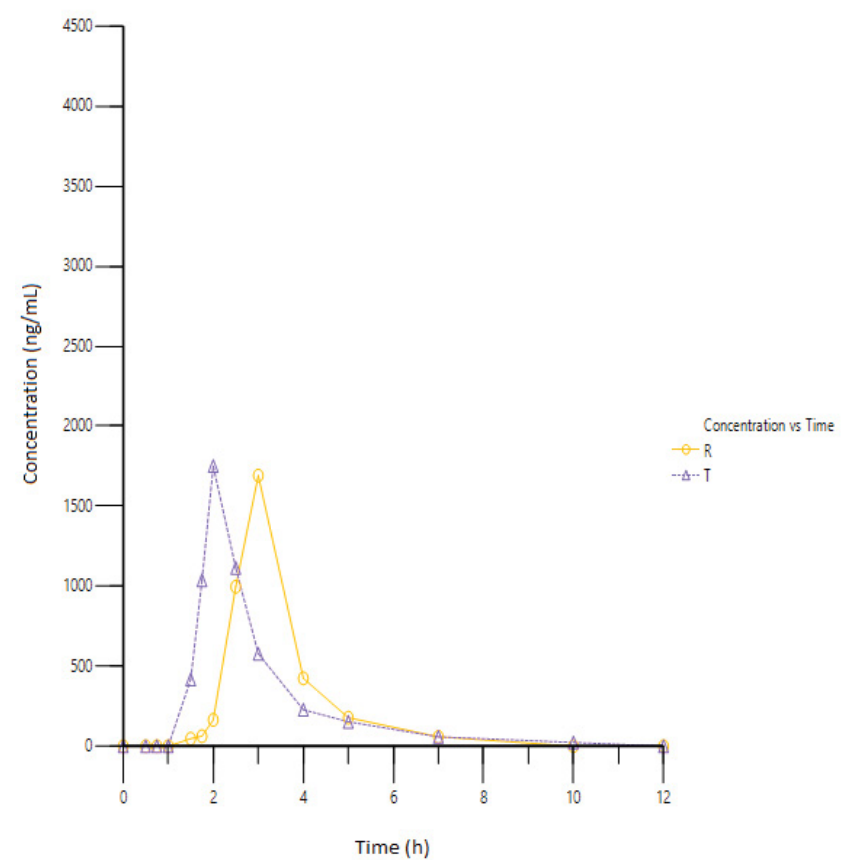

Figure 2L: Concentration curves individual-time for each treatment. Subject 12- Arithmetic Scale- $\mathrm{R}=$ Reference Product $/ \mathrm{T}=$ Test Product 
Citation: Maligne GE, Feleder EC, Yerino GA, Otero AM, Roldán EJA (2018) Bioequivalence of Two Oral Dimethyl Fumarate Extended Release Capsules in Healthy Subjects: A Randomized, Open Label, Single-Dose, 2-Way Crossover Study. J Bioequiv Availab 10: 58-74. 378. doi: 10.4172/0975-0851.1000380

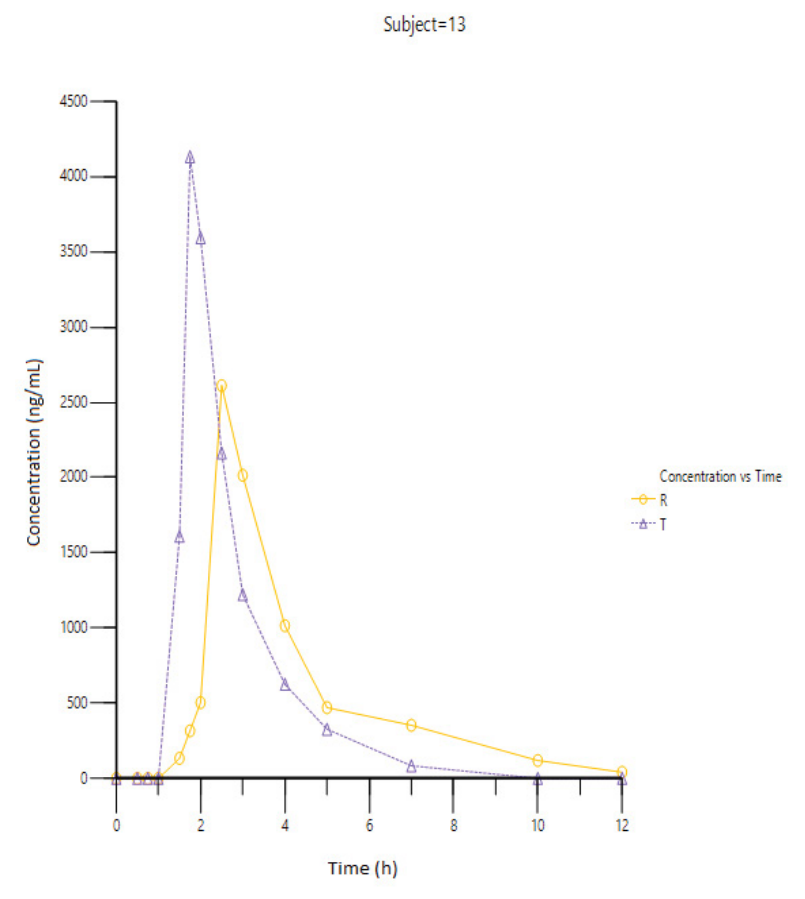

Figure 2M: Concentration curves individual-time for each treatment. Subject 13- Arithmetic Scale- $R=$ Reference Product $/ T=$ Test Product

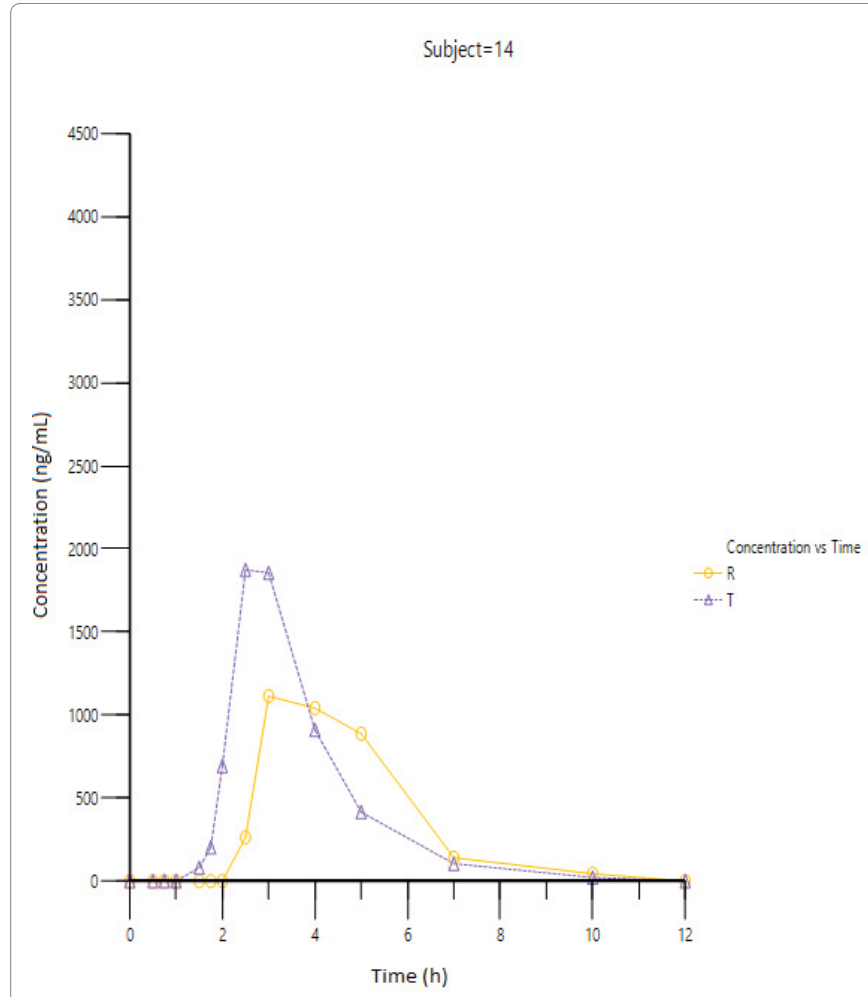

Figure 2N: Concentration curves individual-time for each treatment. Subject 14- Arithmetic Scale-R= Reference Product $/ \mathrm{T}=$ Test Product

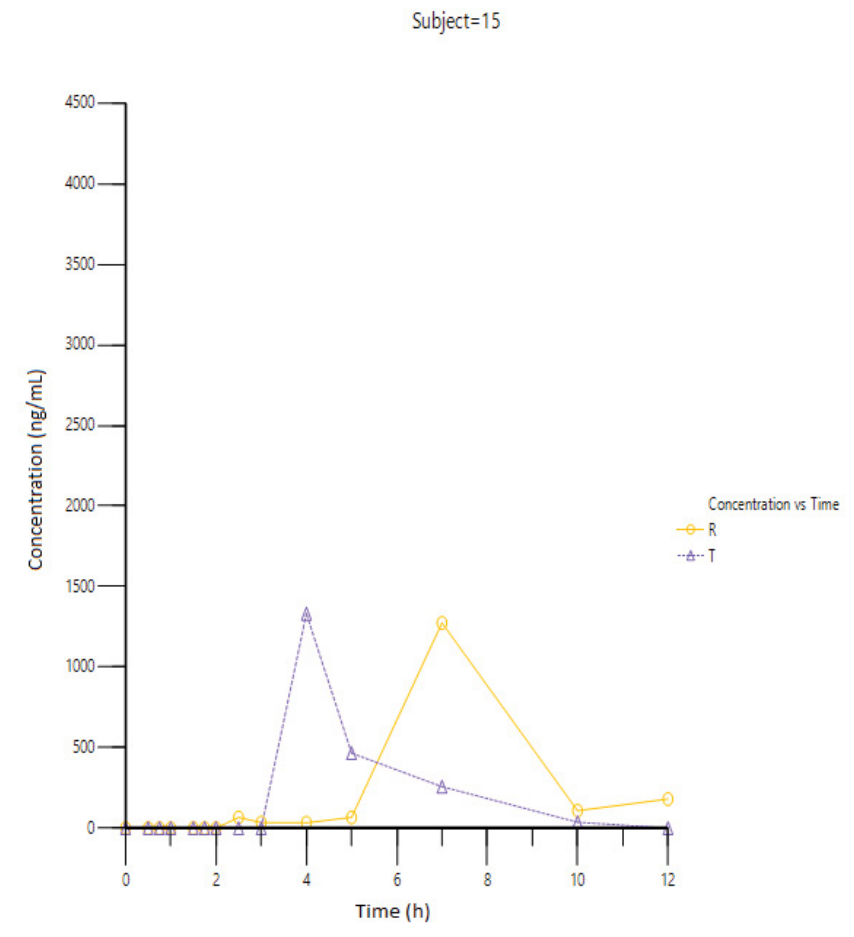

Figure 20: Concentration curves individual-time for each treatment. Subject 15- Arithmetic Scale- $R=$ Reference Product $/ T=$ Test Product

Subject $=16$

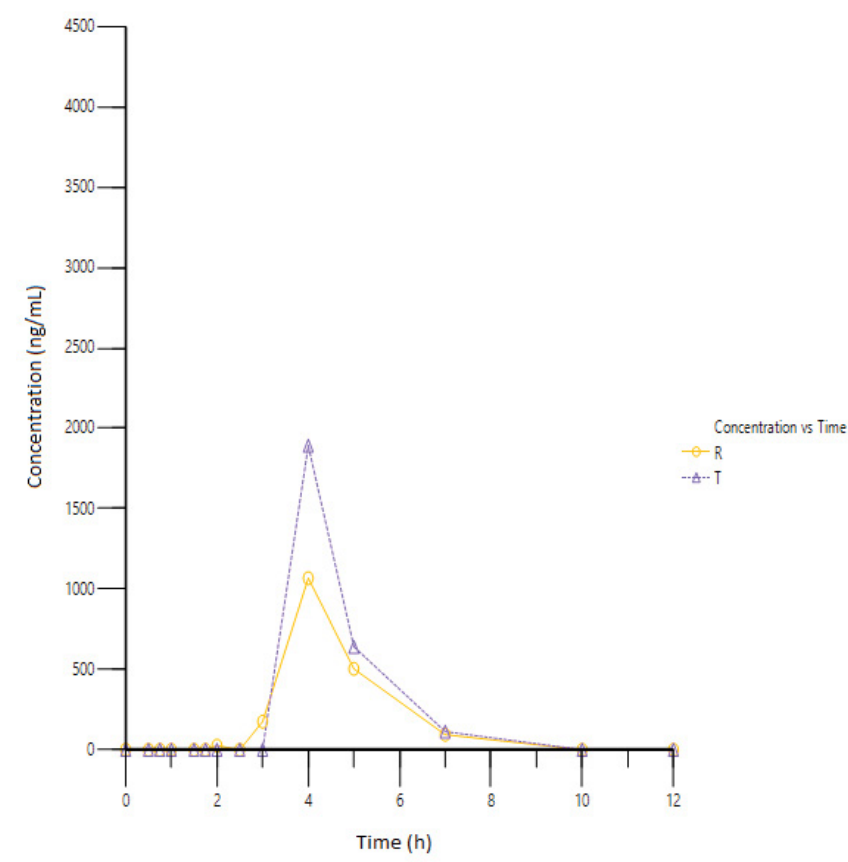

Figure 2P: Concentration curves individual-time for each treatment. Subject 16- Arithmetic Scale- $R=$ Reference Product $/ \mathrm{T}=$ Test Product 
Citation: Maligne GE, Feleder EC, Yerino GA, Otero AM, Roldán EJA (2018) Bioequivalence of Two Oral Dimethyl Fumarate Extended Release Capsules in Healthy Subjects: A Randomized, Open Label, Single-Dose, 2-Way Crossover Study. J Bioequiv Availab 10: 58-74. 378. doi: 10.4172/0975-0851.1000380

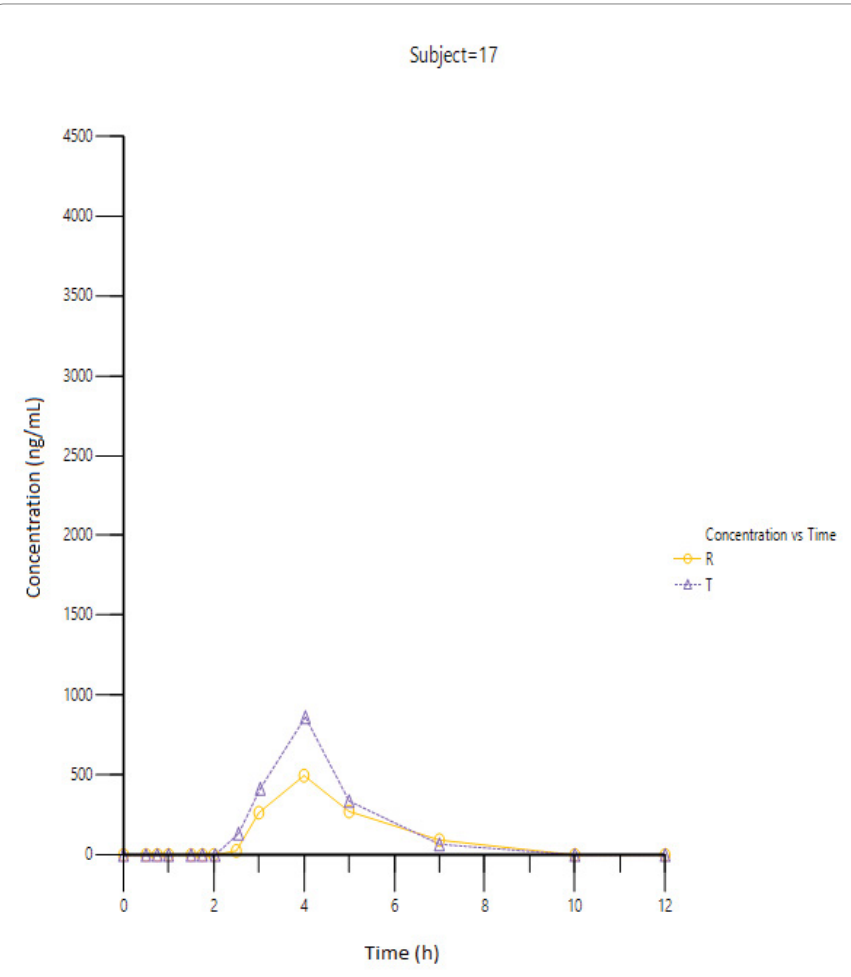

Figure 2Q: Concentration curves individual-time for each treatment. Subject 17- Arithmetic Scale- R= Reference Product $/ \mathrm{T}=$ Test Product

\section{Subject $=18$}

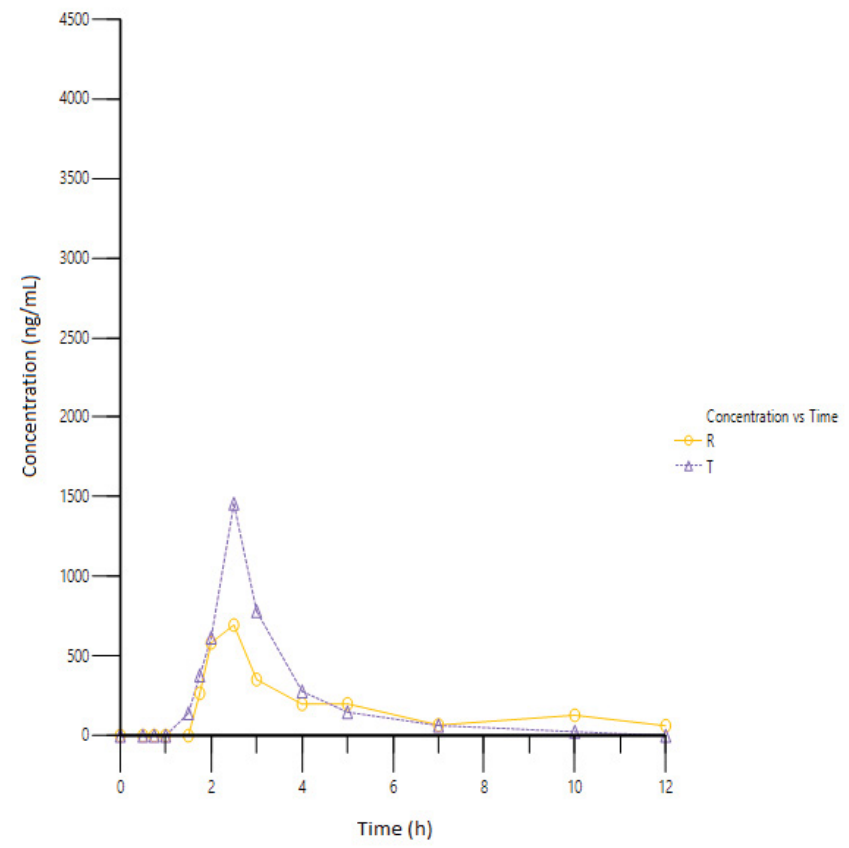

Figure 2R: Concentration curves individual-time for each treatment. Subject 18- Arithmetic Scale- $R=$ Reference Product $/ T=$ Test Product

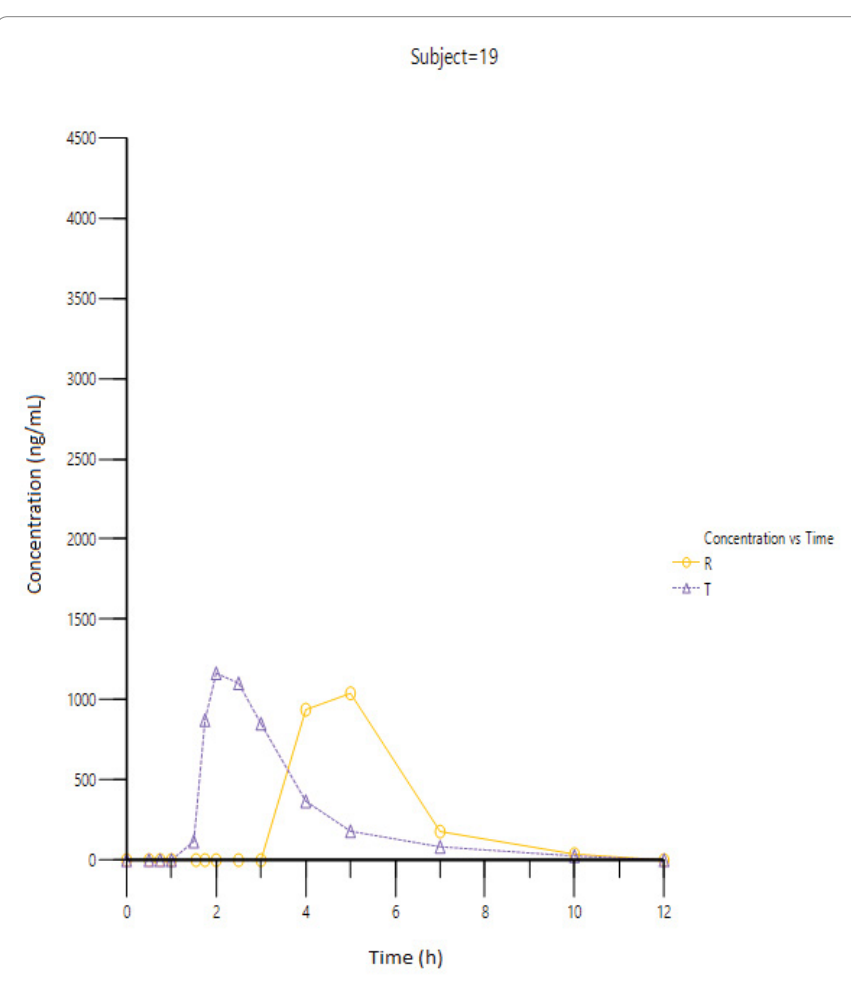

Figure 2S: Concentration curves individual-time for each treatment. Subject 19- Arithmetic Scale- $R=$ Reference Product $/ T=$ Test Product

Subject $=20$

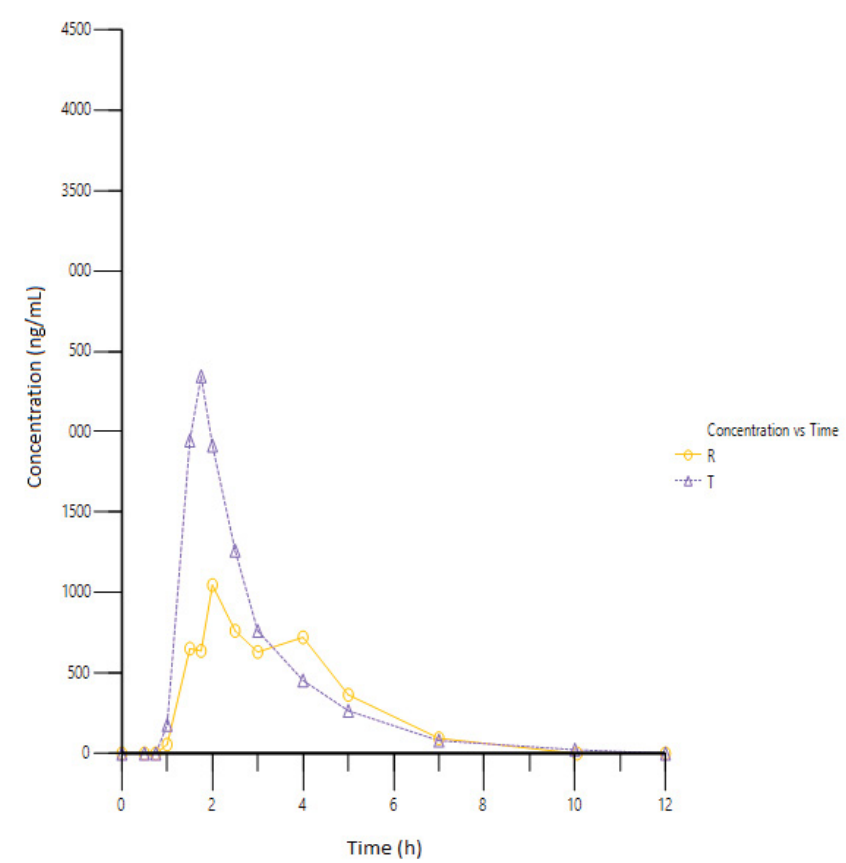

Figure 2T: Concentration curves individual-time for each treatment. Subject 20- Arithmetic Scale- $R=$ Reference Product $/ T=$ Test Product 
Citation: Maligne GE, Feleder EC, Yerino GA, Otero AM, Roldán EJA (2018) Bioequivalence of Two Oral Dimethyl Fumarate Extended Release Capsules in Healthy Subjects: A Randomized, Open Label, Single-Dose, 2-Way Crossover Study. J Bioequiv Availab 10: 58-74. 378. doi: 10.4172/0975-0851.1000380

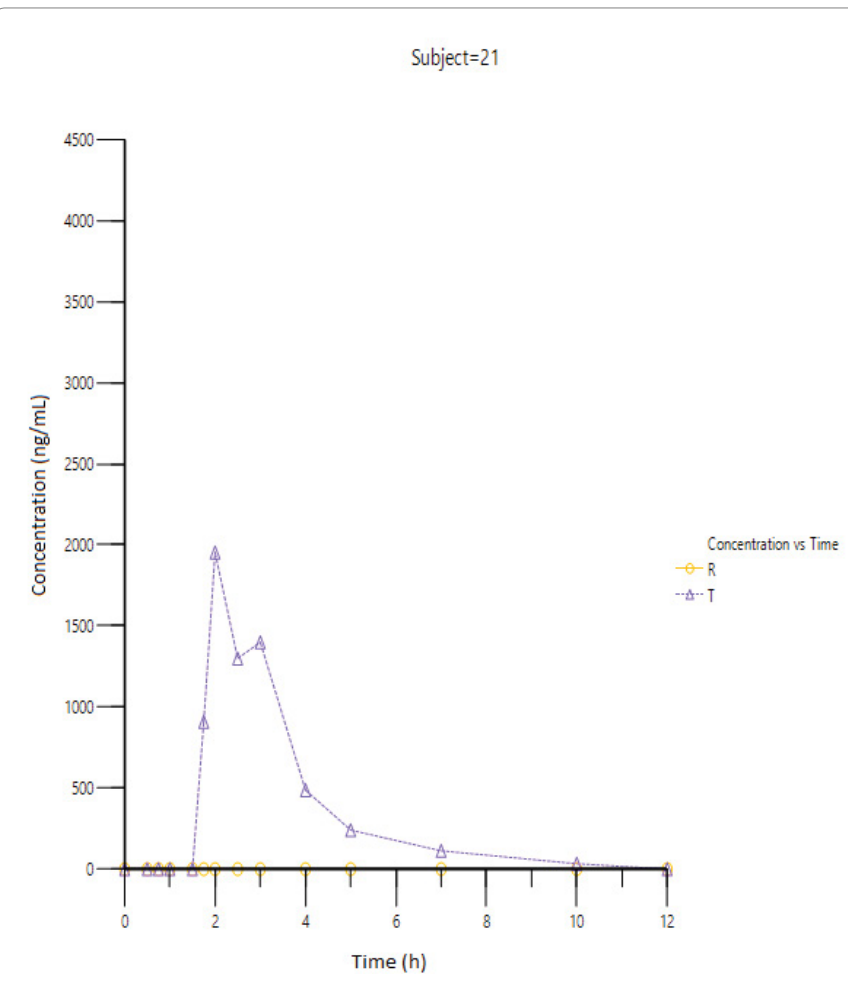

Figure 2U: Concentration curves individual-time for each treatment. Subject 21- Arithmetic Scale- R= Reference Product $/ T=$ Test Product

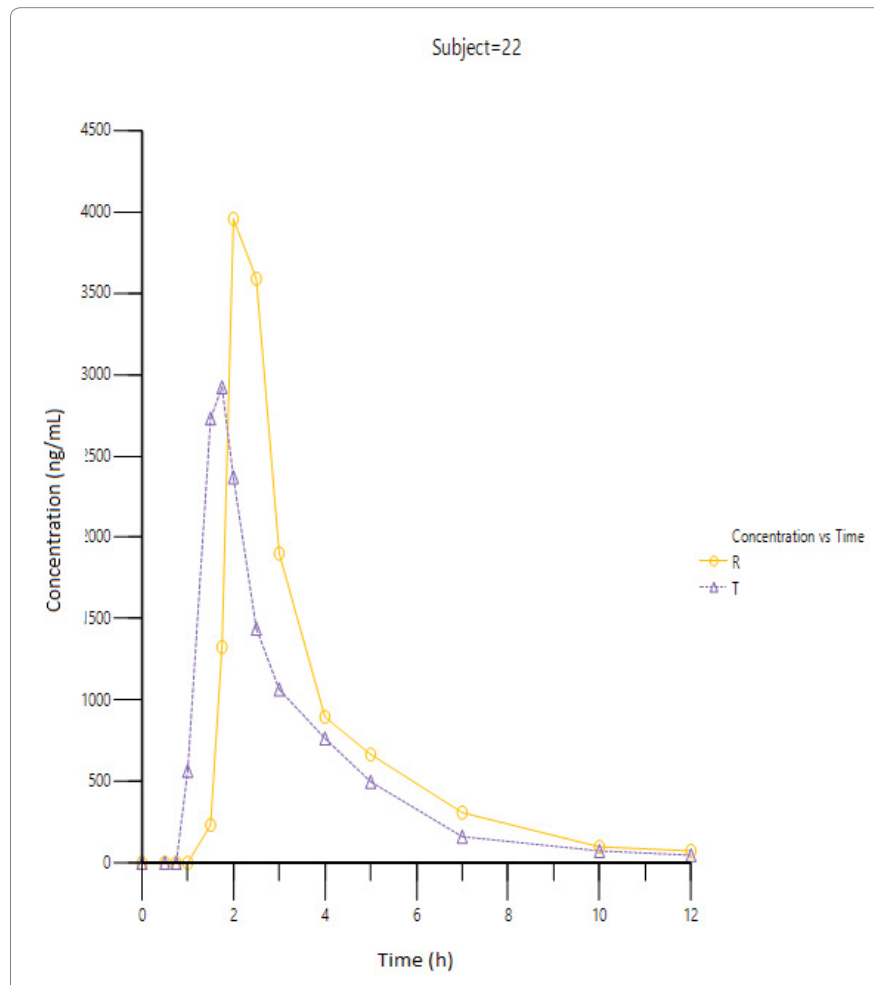

Figure 2V: Concentration curves individual-time for each treatment. Subject 22- Arithmetic Scale- R= Reference Product $/ \mathrm{T}=$ Test Product

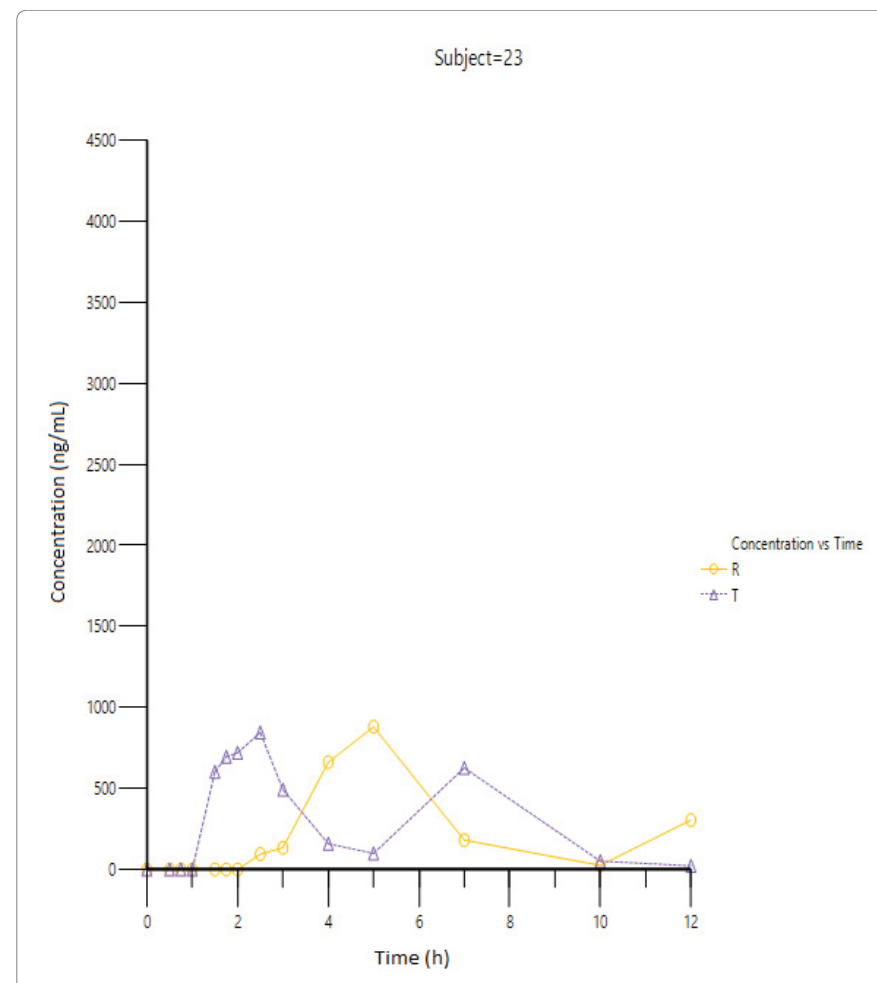

Figure 2W: Concentration curves individual-time for each treatment. Subject 23- Arithmetic Scale-R= Reference Product $/ \mathrm{T}=$ Test Product

Subject $=24$

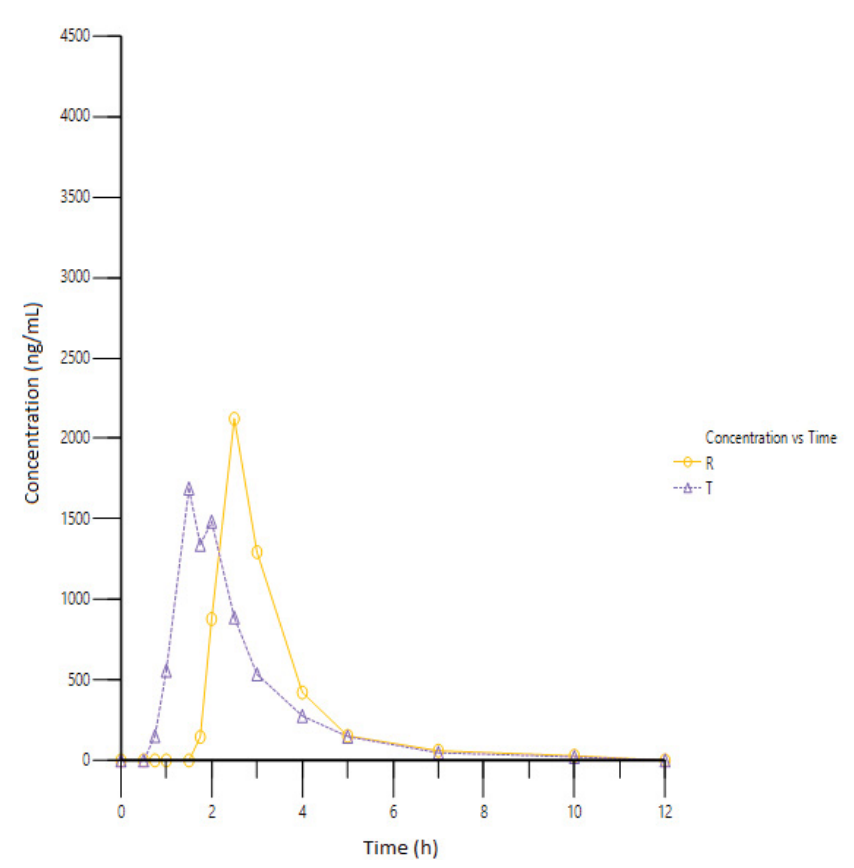

Figure 2X: Concentration curves individual-time for each treatment. Subject 24- Arithmetic Scale- $\mathrm{R}=$ Reference Product $/ \mathrm{T}=$ Test Product 
Citation: Maligne GE, Feleder EC, Yerino GA, Otero AM, Roldán EJA (2018) Bioequivalence of Two Oral Dimethyl Fumarate Extended Release Capsules in Healthy Subjects: A Randomized, Open Label, Single-Dose, 2-Way Crossover Study. J Bioequiv Availab 10: 58-74. 378. doi: 10.4172/0975-0851.1000380

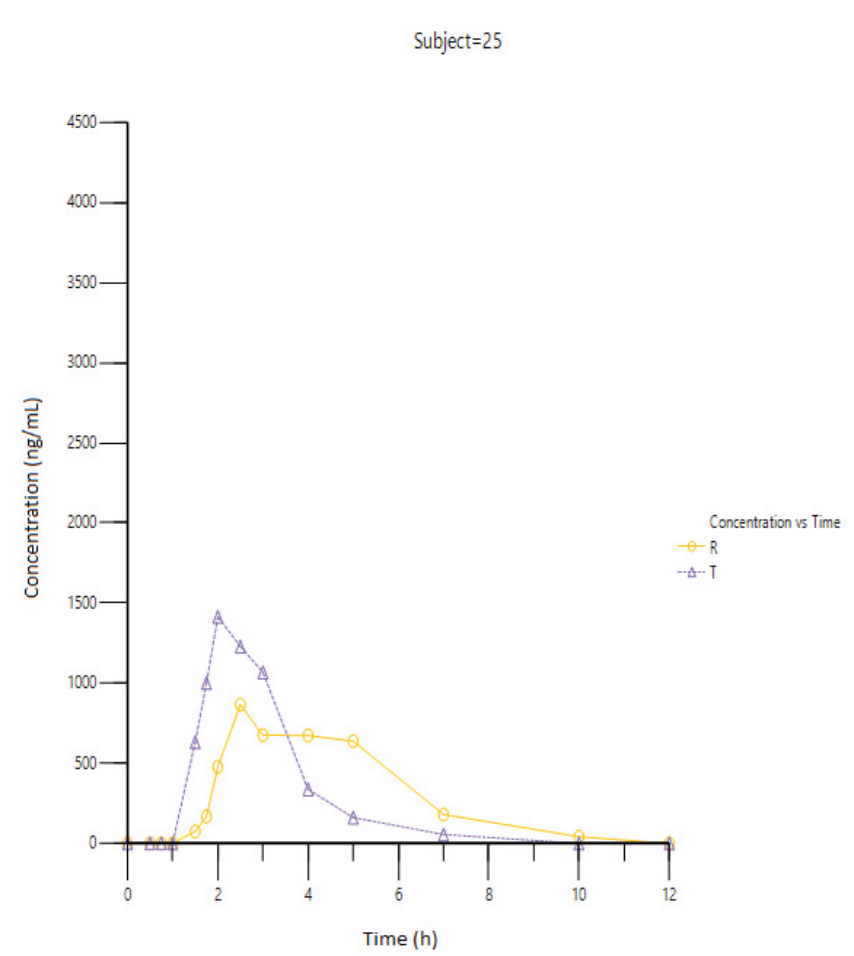

Figure 2Y: Concentration curves individual-time for each treatment. Subject 25- Arithmetic Scale- $R=$ Reference Product $/ T=$ Test Product

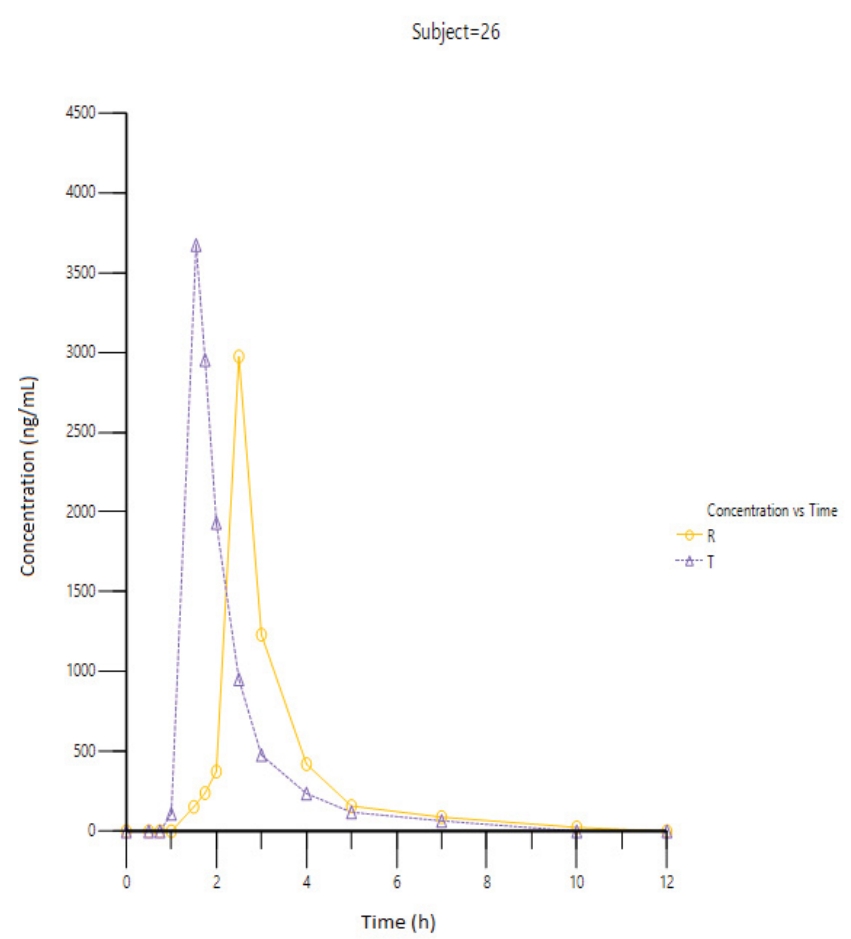

Figure 2Z: Concentration curves individual-time for each treatment. Subject 26- Arithmetic Scale- R= Reference Product $/ \mathrm{T}=$ Test Product

\begin{tabular}{|c|c|c|c|c|c|c|}
\hline & $\begin{array}{c}\text { Cmax } \\
\text { (ng/ml) }\end{array}$ & $\begin{array}{c}\text { Tmax } \\
\text { (h) }\end{array}$ & $\begin{array}{c}\text { ABC0-t } \\
\left(h^{*} n g / m l\right)\end{array}$ & $\lambda(1 / h)$ & $\begin{array}{c}\text { Half } \\
\text { Life }(h)\end{array}$ & ABC0-inf $\left(h^{*} n g / m l\right)$ \\
\hline $\mathrm{N}$ & 26 & 25 & 26 & 19 & 19 & 19 \\
\hline Arithmetic mean & 1561.48 & 3.32 & 3440.14 & 0.43 & 1.79 & 4080.51 \\
\hline Standard Deviation & 1080.87 & 1.51 & 1763.94 & 0.13 & 0.74 & 1616.82 \\
\hline Median & 1193.6 & 2.5 & 3287.64 & 0.41 & 1.71 & 3726.42 \\
\hline Geometric mean & - & 3.04 & - & 0.41 & 1.69 & 3833.75 \\
\hline CV\% & 69.2 & 45.6 & 51.3 & 30.1 & 41.1 & 39.6 \\
\hline Minimum & 0 & 1.5 & 0 & 0.16 & 1.02 & 2139.29 \\
\hline $1^{\circ} \mathrm{Q}$ & 859.75 & 2.5 & 2473.71 & 0.35 & 1.28 & 3171.95 \\
\hline $3^{\circ} \mathrm{Q}$ & 2133.3 & 4 & 3772.48 & 0.54 & 1.99 & 4726.47 \\
\hline Maximum & 4434.9 & 7 & 8112.41 & 0.68 & 4.46 & 8336.62 \\
\hline
\end{tabular}

Table 1A: Summary of pharmacokinetic parameters - Reference Product.

\begin{tabular}{|c|c|c|c|c|c|c|}
\hline & $\begin{array}{c}\text { Cmax } \\
\text { (ng/ml) }\end{array}$ & $\begin{array}{c}\text { Tmax } \\
\text { (h) }\end{array}$ & $\begin{array}{c}\text { ABCo-t } \\
\left(h^{*} n g / m l\right)\end{array}$ & $\lambda(1 / h)$ & $\begin{array}{c}\text { Half } \\
\text { Life }(h)\end{array}$ & ABC0-inf (h*ng/ml) \\
\hline $\mathrm{N}$ & 26 & 26 & 26 & 23 & 23 & 23 \\
\hline Arithmetic mean & 1759.14 & 2.46 & 3546.93 & 0.47 & 1.58 & 3835.41 \\
\hline Standard Deviation & 923.02 & 0.97 & 1339.06 & 0.11 & 0.43 & 1264.38 \\
\hline Median & 1565.6 & 2 & 3378.65 & 0.48 & 1.44 & 3831.63 \\
\hline Geometric mean & 1541.1 & 2.3 & 3290.78 & 0.45 & 1.53 & 3643.77 \\
\hline CV\% & 52.5 & 39.5 & 37.8 & 24.2 & 27 & 33 \\
\hline Minimum & 478.8 & 1.5 & 1084.13 & 0.25 & 1.03 & 1818.95 \\
\hline $1^{\circ} \mathrm{Q}$ & 1010.53 & 1.75 & 2721.9 & 0.39 & 1.3 & 2834.07 \\
\hline $3^{\circ} \mathrm{Q}$ & 2346.45 & 2.63 & 4189.42 & 0.54 & 1.78 & 4433.86 \\
\hline Maximum & 4132.5 & 5 & 6522.5 & 0.67 & 2.81 & 6714.24 \\
\hline
\end{tabular}

Table 1B: Summary of pharmacokinetic parameters - Test Product. 
Citation: Maligne GE, Feleder EC, Yerino GA, Otero AM, Roldán EJA (2018) Bioequivalence of Two Oral Dimethyl Fumarate Extended Release Capsules in Healthy Subjects: A Randomized, Open Label, Single-Dose, 2-Way Crossover Study. J Bioequiv Availab 10: 58-74. 378. doi: 10.4172/0975-0851.1000380

\begin{tabular}{|c|c|c|c|c|c|c|c|c|c|}
\hline Parameter & Unit & MCM Ref & MCM Test & Ratio [\%Ref] & IC90\% Lower & IC90\% Upper & Prob $<80.00$ & Prob $>125.00$ & Power \\
\hline LnCmax & $\mathrm{ng} / \mathrm{ml}$ & 7.21 & 7.34 & 113.7 & 97.27 & 132.9 & 0 & 0.15 & 0.77 \\
\hline LnABC0-t & $h^{*} n g / m l$ & 8.09 & 8.1 & 100.97 & 90.59 & 112.54 & 0 & 0 & 0.96 \\
\hline LnABC0-inf & $h^{*} n g / m l$ & 8.21 & 8.2 & 98.99 & 93.29 & 105.05 & 0 & 0 & 1 \\
\hline
\end{tabular}

Table 1C: Bioequivalence summary.

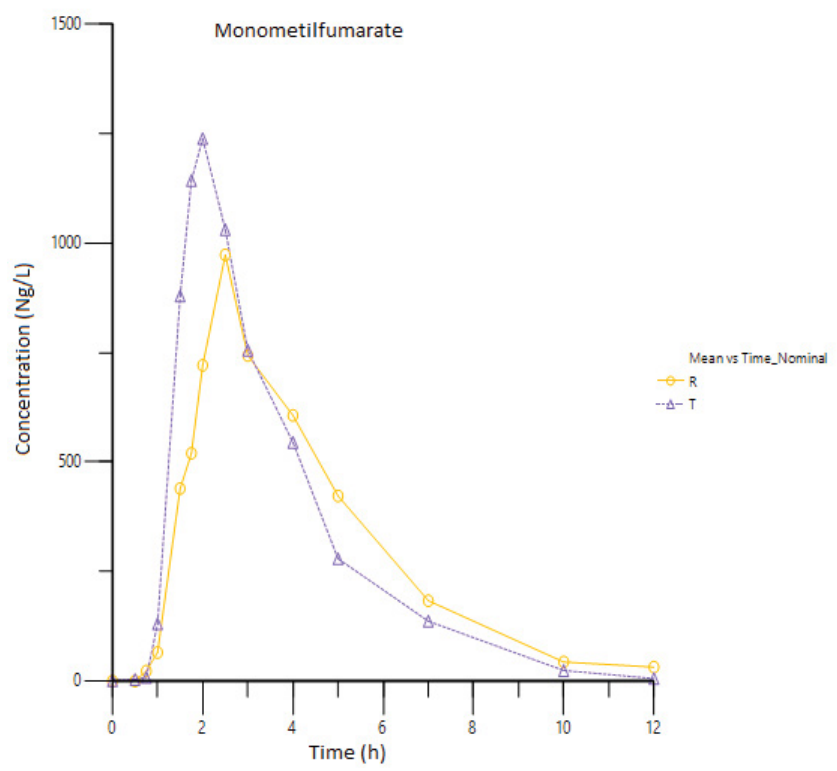

Figure 3A: Time- concentration curves Mean-time concentration curves for each treatment $(n=26)$. Arithmetic Scale- $R=$ Reference Product $/ T=$ Test Product

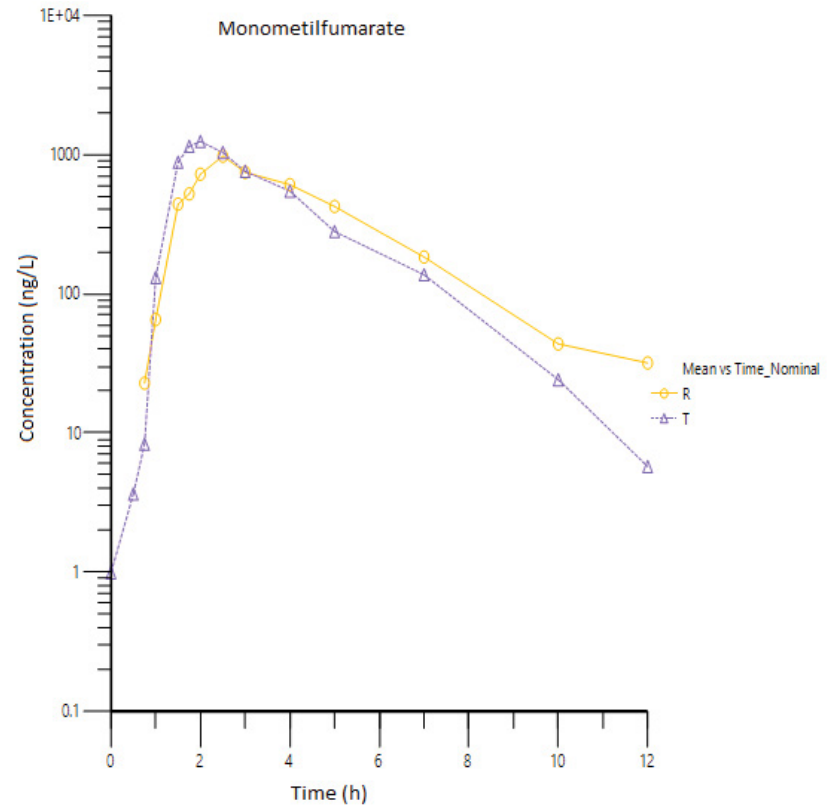

Figure 3B: Mean-time concentration curves for each treatment $(n=26)$. Semi logarithmic Scale- $R=$ Reference Product $/$ T= Test Product 
Citation: Maligne GE, Feleder EC, Yerino GA, Otero AM, Roldán EJA (2018) Bioequivalence of Two Oral Dimethyl Fumarate Extended Release Capsules in Healthy Subjects: A Randomized, Open Label, Single-Dose, 2-Way Crossover Study. J Bioequiv Availab 10: 58-74. 378. doi: 10.4172/0975-0851.1000380

\begin{tabular}{|c|c|c|c|c|c|c|c|c|c|c|c|c|c|c|}
\hline \multirow[b]{2}{*}{ Subject } & \multicolumn{14}{|c|}{ Time (hours) } \\
\hline & 0.00 & 0.50 & 0.75 & 1.00 & 1.50 & 1.75 & 2.00 & 2.50 & 3.00 & 4.00 & 5.00 & 7.00 & 10.00 & 12.00 \\
\hline 1 & 0 & 0.00 & 0. & & 0 & 66 & 490.60 & 1034 & 750.80 & 614.80 & 337.70 & 190.90 & 45.20 & 29.00 \\
\hline 2 & 0.00 & 0.00 & 0.00 & 0.00 & 0.00 & 52.40 & 1378.50 & 2166.30 & 1172.30 & 501.50 & 240.20 & 100.10 & 30.90 & 0.00 \\
\hline 3 & 0.00 & 0.00 & 0.00 & 0.00 & 2937.80 & 2596.50 & 1394.10 & 668.80 & 438.00 & 249.50 & 164.70 & 91.60 & 29.80 & 0.00 \\
\hline 4 & 0.00 & 0.00 & 81.10 & 462.80 & 562.10 & 527.60 & 539.30 & 483.50 & 454.70 & 468.50 & 763.30 & 226.90 & 71.10 & 44.30 \\
\hline 5 & 0.00 & 0.00 & 0.00 & 0.00 & 0.00 & 81.80 & 192.00 & 444.50 & 842.20 & 462.90 & 261.60 & 79.90 & 35.90 & 0.00 \\
\hline 6 & 0.00 & 0.00 & 0.00 & 0.00 & 0.00 & 0.00 & 30.40 & 828.80 & 1352.40 & 1509.70 & 639.10 & 229.20 & 112.00 & 34.00 \\
\hline 7 & 0.00 & 0.00 & 0.00 & 0.00 & 0.00 & 0.00 & 0.00 & 0.00 & 0.00 & 0.00 & 141.70 & 273.10 & 53.90 & 0.00 \\
\hline 8 & 0.00 & 0.00 & 0.00 & 532.30 & 4434.90 & 4391.30 & 3658.70 & 1817.50 & 1003.40 & 527.00 & 273.00 & 110.20 & 35.50 & 0.00 \\
\hline 9 & 0.00 & 0.00 & 0.00 & 47.30 & 1030.90 & 1233.10 & 1605.30 & 1837.00 & 1200.80 & 604.30 & 381.60 & 96.00 & 26.80 & 32.80 \\
\hline 10 & 0.00 & 0.00 & 0.00 & 0.00 & 0.00 & 0.00 & 0.00 & 0.00 & 0.00 & 1536.90 & 1142.40 & 150.80 & 36.10 & 24.00 \\
\hline 11 & 0.00 & 0.00 & 509.60 & 595.40 & 1161.50 & 1398.80 & 1431.00 & 931.30 & 582.50 & 271.90 & 161.20 & 44.50 & 0.00 & 0.00 \\
\hline 12 & 0.00 & 0.00 & 0.00 & 0.00 & 47.20 & 62.70 & 164.60 & 996.80 & 1691.30 & 424.40 & 178.40 & 59.00 & 0.00 & 0.00 \\
\hline 13 & 0.00 & 0.00 & 0.00 & 0.00 & 133.30 & 316.80 & 504.00 & 2610.90 & 2014.40 & 1015.10 & 470.50 & 353.20 & 118.90 & 41.10 \\
\hline 14 & 0.00 & 0.00 & 0.00 & 0.00 & 0.00 & 0.00 & 0.00 & 263.10 & 1113.30 & 1040.70 & 886.80 & 140.30 & 44.20 & 0.00 \\
\hline 15 & 0.00 & 0.00 & 0.00 & 0.00 & 0.00 & 0.00 & 0.00 & 65.90 & 34.40 & 33.00 & 66.40 & 1273.90 & 108.00 & 180.40 \\
\hline 16 & 0.00 & 0.00 & 0.00 & 0.00 & 0.00 & 0.00 & 25.10 & 0.00 & 174.40 & 1067.30 & 503.40 & 93.30 & 0.00 & 0.00 \\
\hline 17 & 0.00 & 0.00 & 0.00 & 0.00 & 0.00 & 0.00 & 0.00 & 25.50 & 264.30 & 496.30 & 272.40 & 93.00 & 0.00 & 0.00 \\
\hline 18 & 0.00 & 0.00 & 0.00 & 0.00 & 0.00 & 265.70 & 583.20 & 694.70 & 352.60 & 198.00 & 199.30 & 66.80 & 128.00 & 62.20 \\
\hline 19 & 0.00 & 0.00 & 0.00 & 0.00 & 0.00 & 0.00 & 0.00 & 0.00 & 0.00 & 937.10 & 1038.90 & 177.60 & 37.10 & 0.00 \\
\hline 20 & 0.00 & 0.00 & 0.00 & 55.80 & 651.40 & 637.30 & 1046.50 & 762.00 & 630.50 & 721.40 & 364.20 & 94.30 & 0.00 & 0.00 \\
\hline 21 & 0.00 & 0.00 & 0.00 & 0.00 & 0.00 & 0.00 & 0.00 & 0.00 & 0.00 & 0.00 & 0.00 & 0.00 & 0.00 & 0.00 \\
\hline 22 & 0.00 & 0.00 & 0.00 & 0.00 & 233.00 & 1326.40 & 3956.70 & 3589.50 & 1901.70 & 896.80 & 666.20 & 309.00 & 98.50 & 73.80 \\
\hline 23 & 0.00 & 0.00 & 0.00 & 0.00 & 0.00 & 00 & 0.00 & 94.80 & 134.50 & 661.60 & 880.00 & 181.20 & 25.70 & 305.50 \\
\hline 24 & 0.00 & 0.00 & 0.00 & 0.00 & 0.00 & 145.90 & 878.60 & 2122.30 & 1294.10 & 422.30 & 152.50 & 60.40 & 29.30 & 0.00 \\
\hline 25 & 0.00 & 0.00 & 0.00 & 0.00 & 74.00 & 168.00 & 477.40 & 865.60 & 675.70 & 673.00 & 637.70 & 180.40 & 41.80 & 0.00 \\
\hline 26 & 0.00 & 0.00 & 0.00 & 0.00 & 152.70 & 239.30 & 373.70 & 2973.60 & 1230.80 & 420.40 & 158.10 & 88.60 & 24.00 & 0.00 \\
\hline $\mathrm{N}$ & 26 & , & 26 & 26 & 26 & 26 & 26 & 26 & 26 & 26 & 26 & 26 & 26 & 26 \\
\hline Arithmetic mean & 0.00 & 0.00 & 22.72 & 65.14 & 439.19 & 519.62 & 720.37 & 972.20 & 742.66 & 605.94 & 422.36 & 183.24 & 43.57 & 31.81 \\
\hline Median & 0.00 & 0.00 & 0.00 & 0 & 0.00 & 74.10 & 425.55 & 728.35 & 653.10 & 514.25 & 305.35 & 105.15 & 35.70 & 0.00 \\
\hline Standard Deviation & 0.00 & 0.00 & 100.57 & 172.87 & 1030.33 & 1004.43 & 1047.73 & 1024.44 & 612.69 & 405.23 & 315.47 & 238.18 & 39.33 & 68.17 \\
\hline CV\% & 0.00 & 0.00 & 442.70 & 265.40 & 234.60 & 193.30 & 145.40 & 105.40 & 82.50 & 66.90 & 74.70 & 130.00 & 90.30 & 214.30 \\
\hline Minimum & 0.00 & 0.00 & 0.00 & 0.00 & 0.00 & 00 & 0.00 & 0 & 00 & 0 & 0.00 & 0.00 & 0.00 & 0.00 \\
\hline $1^{\circ} \mathrm{Q}$ & 0.00 & 0.00 & 0.00 & 0.0 & 0.00 & 0.00 & 0.00 & 0.00 & 164.43 & 383.28 & 163.83 & 86.43 & 18.00 & 0.00 \\
\hline $3^{\circ} \mathrm{Q}$ & 0.00 & 0.00 & 0.00 & 0.00 & 315.28 & 555.03 & 1129.50 & 1822.38 & 1208.30 & 906.88 & 645.88 & 199.90 & 58.20 & 35.78 \\
\hline Maximum & 0.00 & 0.00 & 509.60 & 595.40 & 4434.90 & 4391.30 & 3956.70 & 3589.50 & 2014.40 & 1536.90 & 1142.40 & 1273.90 & 128.00 & 305.50 \\
\hline
\end{tabular}

Table 2A: Pharmacokinetic and statistical results.

Pharmacokinetic tables - Plasmatic-time concentration ( $\mathrm{ng} / \mathrm{ml})$. Reference Product

\section{Safety and tolerability}

Safety and tolerability was assessed in 26 subjects who received the investigational product. DMF extended release capsules was well tolerated by all subjects. No clinically significant changes in vital signs (blood pressure, heart rate or axillary temperature) were observed after single oral dose of DMF $12 \mathrm{mg}$. No side adverse events were reported during the study. No adverse events were considered to be related to the investigational product (Table 5). All related adverse events were of mild intensity and they resolved without treatment.

\section{Discussion}

The objective of the present study was to evaluate and compare rate and extent of absorption of a new pharmaceutical equivalent extended-released formulation containing DMF $240 \mathrm{mg}$ to that from 
Citation: Maligne GE, Feleder EC, Yerino GA, Otero AM, Roldán EJA (2018) Bioequivalence of Two Oral Dimethyl Fumarate Extended Release Capsules in Healthy Subjects: A Randomized, Open Label, Single-Dose, 2-Way Crossover Study. J Bioequiv Availab 10: 58-74. 378. doi: 10.4172/0975-0851.1000380

\begin{tabular}{|c|c|c|c|c|c|c|c|c|c|c|c|c|c|c|}
\hline Subject & 0.00 & 0.50 & 0.75 & 1.00 & 1.50 & 1.75 & 2.00 & 2.50 & 3.00 & 4.00 & 5.00 & 7.00 & 10.00 & 12.00 \\
\hline 1 & 0.00 & 94.80 & 0.00 & 0.00 & 0.00 & 0.00 & 0.00 & 0.00 & 121.30 & 478.80 & 295.60 & 0.00 & 23.60 & 0.00 \\
\hline 2 & 0.00 & 0.00 & 0.00 & 1194.30 & 2352.60 & 2034.10 & 1337.80 & 806.90 & 511.00 & 294.40 & 163.80 & 64.00 & 20.40 & 0.00 \\
\hline 3 & 0.00 & 0.00 & 0.00 & 0.00 & 0.00 & 87.30 & 1436.50 & 1673.80 & 866.20 & 411.50 & 242.60 & 115.50 & 41.00 & 23.50 \\
\hline 4 & 0.00 & 0.00 & 0.00 & 0.00 & 0.00 & 216.80 & 701.20 & 1010.30 & 894.20 & 671.20 & 313.70 & 129.90 & 54.70 & 28.00 \\
\hline 5 & 0.00 & 0.00 & 0.00 & 207.60 & 628.80 & 666.60 & 633.30 & 545.20 & 345.90 & 169.90 & 156.10 & 54.30 & 0.00 & 0.00 \\
\hline 6 & 0.00 & 0.00 & 0.00 & 226.40 & 2769.70 & 2437.40 & 2506.10 & 1442.90 & Missing & 421.00 & 268.20 & 105.50 & 38.40 & 0.00 \\
\hline 7 & 0.00 & 0.00 & 0.00 & 0.00 & 0.00 & 0.00 & 0.00 & 0.00 & 0.00 & 120.30 & 746.70 & 268.20 & 32.90 & 27.40 \\
\hline 8 & 25.80 & 0.00 & 0.00 & 0.00 & 1949.30 & 2881.50 & 2731.00 & 1957.10 & 1173.10 & 499.40 & 267.10 & 126.80 & 24.00 & 0.00 \\
\hline 9 & 0.00 & 0.00 & 0.00 & 0.00 & 329.40 & 1172.80 & 1387.70 & 1225.60 & 1251.70 & 768.10 & 252.90 & 124.30 & 34.40 & 0.00 \\
\hline 10 & 0.00 & 0.00 & 64.50 & 358.00 & 1018.40 & 1219.70 & 1263.70 & 1451.50 & 1197.70 & 401.70 & 210.90 & 72.90 & 0.00 & 0.00 \\
\hline 11 & 0.00 & 0.00 & 0.00 & 0.00 & 157.70 & 190.40 & 577.60 & 907.50 & 1010.60 & 712.10 & 141.40 & 509.90 & 21.20 & 0.00 \\
\hline 12 & 0.00 & 0.00 & 0.00 & 0.00 & 417.10 & 1037.30 & 1751.20 & 1114.50 & 578.00 & 227.90 & 152.80 & 58.50 & 23.40 & 0.00 \\
\hline 13 & 0.00 & 0.00 & 0.00 & 0.00 & 1609.40 & 4132.50 & 3594.00 & 2163.50 & 1221.70 & 625.30 & 326.70 & 84.10 & 0.00 & 0.00 \\
\hline 14 & 0.00 & 0.00 & 0.00 & 0.00 & 80.80 & 203.30 & 692.70 & 1874.00 & 1855.20 & 909.70 & 414.80 & 104.80 & 21.80 & 0.00 \\
\hline 15 & 0.00 & 0.00 & 0.00 & 0.00 & 0.00 & 0.00 & 0.00 & 0.00 & 0.00 & 1331.40 & 465.60 & 257.40 & 36.90 & 0.00 \\
\hline 16 & 0.00 & 0.00 & 0.00 & 0.00 & 0.00 & 0.00 & 0.00 & 0.00 & 0.00 & 1892.00 & 640.40 & 112.60 & 0.00 & 0.00 \\
\hline 17 & 0.00 & 0.00 & 0.00 & 0.00 & 0.00 & 0.00 & 0.00 & 133.10 & 414.30 & 862.50 & 336.80 & 67.00 & 0.00 & 0.00 \\
\hline 18 & 0.00 & 0.00 & 0.00 & 0.00 & 140.60 & 378.50 & 615.00 & 1457.40 & 781.40 & 278.00 & 147.60 & 63.90 & 24.60 & 0.00 \\
\hline 19 & 0.00 & 0.00 & 0.00 & 0.00 & 116.30 & 872.10 & 1164.50 & 1101.70 & 849.90 & 367.10 & 179.70 & 82.70 & 25.60 & 0.00 \\
\hline 20 & 0.00 & 0.00 & 0.00 & 177.90 & 1944.60 & 2344.40 & 1914.20 & 1261.50 & 761.50 & 453.80 & 265.20 & 79.80 & 23.30 & 0.00 \\
\hline 21 & 0.00 & 0.00 & 0.00 & 0.00 & 0.00 & 908.90 & 1953.40 & 1299.30 & 1399.30 & 487.40 & 240.70 & 112.80 & 33.20 & 0.00 \\
\hline 22 & 0.00 & 0.00 & 0.00 & 566.00 & 2730.60 & 2922.50 & 2369.60 & 1439.50 & 1065.80 & 764.90 & 498.50 & 161.40 & 73.80 & 47.30 \\
\hline 23 & 0.00 & 0.00 & 0.00 & 0.00 & 603.00 & 695.40 & 719.70 & 845.20 & 492.70 & 159.00 & 99.40 & 626.80 & 51.70 & 23.00 \\
\hline 24 & 0.00 & 0.00 & 151.50 & 557.90 & 1690.00 & 1339.50 & 1483.80 & 888.00 & 535.50 & 276.40 & 148.20 & 47.40 & 22.00 & 0.00 \\
\hline 25 & 0.00 & 0.00 & 0.00 & 0.00 & 632.20 & 1001.20 & 1414.60 & 1229.50 & 1067.30 & 337.30 & 161.10 & 55.20 & 0.00 & 0.00 \\
\hline 26 & 0.00 & 0.00 & 0.00 & 110.70 & 3672.10 & 2952.40 & 1931.10 & 951.90 & 477.10 & 236.10 & 118.90 & 65.30 & 0.00 & 0.00 \\
\hline \multirow[t]{2}{*}{$N$} & 26 & 26 & 26 & 26 & 26 & 26 & 26 & 26 & 25 & 26 & 26 & 26 & 26 & 26 \\
\hline & 0.99 & 3.65 & 8.31 & 130.72 & 878.56 & 1142.10 & 1237.64 & 1030.00 & 754.86 & 544.51 & 279.05 & 136.58 & 24.11 & 5.74 \\
\hline Median & 0.00 & 0.00 & 0.00 & 0.00 & 373.25 & 890.50 & 1300.75 & 1108.10 & 781.40 & 437.40 & 247.75 & 94.45 & 23.50 & 0.00 \\
\hline Standard Deviation & 5.06 & 18.59 & 31.82 & 274.23 & 1089.01 & 1163.18 & 943.57 & 619.51 & 476.18 & 391.61 & 160.71 & 140.80 & 19.17 & 12.65 \\
\hline $\mathrm{CV} \%$ & 509.90 & 509.90 & 383.10 & 209.80 & 124.00 & 101.80 & 76.20 & 60.10 & 63.10 & 71.90 & 57.60 & 103.10 & 79.50 & 220.30 \\
\hline Minimum & 0.00 & 0.00 & 0.00 & 0.00 & 0.00 & 0.00 & 0.00 & 0.00 & 0.00 & 120.30 & 99.40 & 0.00 & 0.00 & 0.00 \\
\hline $1^{\circ} \mathrm{Q}$ & 0.00 & 0.00 & 0.00 & 0.00 & 0.00 & 164.63 & 605.65 & 741.48 & 445.70 & 277.60 & 155.28 & 63.98 & 0.00 & 0.00 \\
\hline $3^{\circ} \mathrm{Q}$ & 0.00 & 0.00 & 0.00 & 185.33 & 1753.65 & 2111.68 & 1918.43 & 1445.05 & 1120.20 & 725.30 & 329.23 & 127.58 & 35.03 & 0.00 \\
\hline Maximum & 25.80 & 94.80 & 151.50 & 1194.30 & 3672.10 & 4132.50 & 3594.00 & 2163.50 & 1855.20 & 1892.00 & 746.70 & 626.80 & 73.80 & 47.30 \\
\hline
\end{tabular}

Table 2B: Pharmacokinetic tables - Plasmatic-time concentration (ng/ml). Test Product.

the innovator product in healthy volunteers; and secondarily to assess bioequivalence between them. The results of this study demonstrated that no significance differences were found, in terms of rate and extent of absorption, between test and reference products, as indicated by $\mathrm{C}_{\max }$ and AUC comparisons and also by the similar plasma MMF concentration-time curves. The null hypothesis that the estimated parameters exceeded limits of acceptance was rejected, considering that $90 \%$ CIs of the ratios of $\mu \mathrm{T} / \mu \mathrm{R}$ for the PK parameters $\left(\mathrm{C}_{\max }\right.$ and AUCs log-transformed) were found to be within the predetermined range (80\%-125\%) and the Schuirmann's two one-sided $t$ test procedure (probability of exceeding limits of acceptance) found all probability values $<0.05$. 
Citation: Maligne GE, Feleder EC, Yerino GA, Otero AM, Roldán EJA (2018) Bioequivalence of Two Oral Dimethyl Fumarate Extended Release Capsules in Healthy Subjects: A Randomized, Open Label, Single-Dose, 2-Way Crossover Study. J Bioequiv Availab 10: 58-74. 378. doi: 10.4172/0975-0851.1000380

\begin{tabular}{|c|c|c|c|c|c|c|}
\hline Subject & Cmax (ng/ml) & $\operatorname{Tmax}(\mathrm{h})$ & ABC0-t (h*ng /ml) & $\lambda(1 / h)$ & Half Life $(h)$ & $A B C 0$-inf $\left(h^{*} n g / m l\right)$ \\
\hline 1 & 1034.9 & 2.5 & 3021.73 & 0.38 & 1.82 & 3097.94 \\
\hline 2 & 2166.3 & 2.5 & 3650.81 & 0.41 & 1.7 & 3726.42 \\
\hline 3 & 2937.8 & 1.5 & 3706.74 & 0.35 & 1.99 & 3792.28 \\
\hline 4 & 763.3 & 5 & 3724.28 & 0.33 & 2.09 & 3857.93 \\
\hline 5 & 842.2 & 3 & 2055.25 & 0.43 & 1.62 & 2139.29 \\
\hline 6 & 1509.7 & 4 & 4795.45 & 0.39 & 1.77 & 4882.38 \\
\hline 7 & 273.1 & 7 & 976.15 & - & - & - \\
\hline 8 & 4434.9 & 1.5 & 7259.09 & 0.41 & 1.71 & 7346.61 \\
\hline 9 & 1837 & 2.5 & 4650.19 & 0.43 & 1.61 & 4726.47 \\
\hline 10 & 1536.9 & 4 & 3741.75 & 0.38 & 1.84 & 3805.55 \\
\hline 11 & 1431 & 2 & 3133.29 & 0.63 & 1.1 & 3203.62 \\
\hline 12 & 1691.3 & 3 & 2612.98 & 0.64 & 1.08 & 2704.76 \\
\hline 13 & 2610.9 & 2.5 & 6076.64 & 0.42 & 1.63 & 6173.37 \\
\hline 14 & 1113.3 & 3 & 3754.48 & 0.56 & 1.23 & 3833.02 \\
\hline 15 & 1273.9 & 7 & 3826.5 & - & - & - \\
\hline 16 & 1067.3 & 4 & 2055.91 & - & - & - \\
\hline 17 & 496.3 & 4 & 1208.88 & - & - & - \\
\hline 18 & 694.7 & 2.5 & 1943.08 & 0.16 & 4.46 & 2343.13 \\
\hline 19 & 1038.9 & 5 & 2995.1 & - & - & - \\
\hline 20 & 1046.5 & 2 & 3032.84 & 0.68 & 1.02 & 3171.95 \\
\hline 21 & 0 & - & 0 & - & - & - \\
\hline 22 & 3956.7 & 2 & 8112.41 & 0.33 & 2.11 & 8336.62 \\
\hline 23 & 880 & 5 & 2952.63 & - & - & - \\
\hline 24 & 2122.3 & 2.5 & 3243.68 & 0.32 & 2.15 & 3334.41 \\
\hline 25 & 865.6 & 2.5 & 3331.6 & 0.54 & 1.28 & 3408.94 \\
\hline 26 & 2973.6 & 2.5 & 3582.18 & 0.38 & 1.82 & 3645.06 \\
\hline $\mathrm{N}$ & 26 & 25 & 26 & 19 & 19 & 19 \\
\hline Arithmetic mean & 1561.48 & 3.32 & 3440.14 & 0.43 & 1.79 & 4080.51 \\
\hline Standard Deviation & 1080.87 & 1.513 & 1763.94 & 0.13 & 0.74 & 1616.82 \\
\hline Median & 1193.6 & 2.5 & 3287.64 & 0.41 & 1.71 & 3726.42 \\
\hline Geometric mean & - & 3.038 & - & 0.41 & 1.69 & 3833.75 \\
\hline CV\% & 69.2 & 45.6 & 51.3 & 30.1 & 41.1 & 39.6 \\
\hline Minimum & 0 & 1.5 & 0 & 0.16 & 1.02 & 2139.29 \\
\hline $1^{\circ} \mathrm{Q}$ & 859.75 & 2.5 & 2473.71 & 0.35 & 1.28 & 3171.95 \\
\hline $3^{\circ} \mathrm{Q}$ & 2133.3 & 4 & 3772.48 & 0.54 & 1.99 & 4726.47 \\
\hline Maximum & 4434.9 & 7 & 8112.41 & 0.68 & 4.46 & 8336.62 \\
\hline
\end{tabular}

Table 2C: Pharmacokinetic tables - Pharmacokinetic parameters. Reference Product. 
Citation: Maligne GE, Feleder EC, Yerino GA, Otero AM, Roldán EJA (2018) Bioequivalence of Two Oral Dimethyl Fumarate Extended Release Capsules in Healthy Subjects: A Randomized, Open Label, Single-Dose, 2-Way Crossover Study. J Bioequiv Availab 10: 58-74. 378. doi: 10.4172/0975-0851.1000380

\begin{tabular}{|c|c|c|c|c|c|c|}
\hline $\mathbf{T}$ & Cmax (ng/ml) & $\operatorname{Tmax}(\mathrm{h})$ & ABC0-t (h*ng /ml) & $\lambda(1 / h)$ & Half Life (h) & $A B C 0$-inf $\left(h^{*} n g / m l\right)$ \\
\hline 1 & 478.8 & 4 & 1084.13 & - & - & - \\
\hline 2 & 2352.6 & 1.5 & 3857.69 & 0.41 & 1.68 & 3906.98 \\
\hline 3 & 1673.8 & 2.5 & 3237.21 & 0.34 & 2.07 & 3307.3 \\
\hline 4 & 1010.3 & 2.5 & 3124.2 & 0.31 & 2.27 & 3215.87 \\
\hline 5 & 666.6 & 1.75 & 1708.16 & 0.49 & 1.41 & 1818.95 \\
\hline 6 & 2769.7 & 1.5 & 5365.48 & 0.4 & 1.73 & 5461.51 \\
\hline 7 & 746.7 & 5 & 2020.5 & 0.48 & 1.46 & 2078.13 \\
\hline 8 & 2881.5 & 1.75 & 5593.36 & 0.49 & 1.4 & 5641.96 \\
\hline 9 & 1387.7 & 2 & 3998.49 & 0.4 & 1.73 & 4084.21 \\
\hline 10 & 1451.5 & 2.5 & 3726.06 & 0.56 & 1.23 & 3855.44 \\
\hline 11 & 1010.6 & 3 & 3787.52 & 0.48 & 1.44 & 3831.63 \\
\hline 12 & 1751.2 & 2 & 2701.64 & 0.38 & 1.81 & 2762.7 \\
\hline 13 & 4132.5 & 1.75 & 6181.88 & 0.67 & 1.04 & 6307.7 \\
\hline 14 & 1874 & 2.5 & 4495.89 & 0.64 & 1.09 & 4530.09 \\
\hline 15 & 1331.4 & 4 & 2728.65 & 0.52 & 1.34 & 2799.87 \\
\hline 16 & 1892 & 4 & 2965.2 & - & - & - \\
\hline 17 & 862.5 & 4.03 & 1789.84 & - & - & - \\
\hline 18 & 1457.4 & 2.5 & 2388.78 & 0.36 & 1.95 & 2458.04 \\
\hline 19 & 1164.5 & 2 & 2768.4 & 0.39 & 1.78 & 2834.07 \\
\hline 20 & 2344.4 & 1.75 & 4387.79 & 0.51 & 1.37 & 4433.86 \\
\hline 21 & 1953.4 & 2 & 3839.13 & 0.4 & 1.75 & 3922.73 \\
\hline 22 & 2922.5 & 1.75 & 6522.5 & 0.25 & 2.81 & 6714.24 \\
\hline 23 & 845.2 & 2.5 & 3489.34 & 0.67 & 1.03 & 3523.44 \\
\hline 24 & 1690 & 1.5 & 3267.96 & 0.54 & 1.3 & 3309.08 \\
\hline 25 & 1414.6 & 2 & 3067.23 & 0.59 & 1.17 & 3160.21 \\
\hline 26 & 3672.1 & 1.55 & 4123.3 & 0.49 & 1.41 & 4256.35 \\
\hline $\mathrm{N}$ & 26 & 26 & 26 & 23 & 23 & 23 \\
\hline Arithmetic mean & 1759.14 & 2.455 & 3546.93 & 0.47 & 1.58 & 3835.41 \\
\hline Standard Deviation & 923.02 & 0.97 & 1339.06 & 0.11 & 0.43 & 1264.38 \\
\hline Median & 1565.6 & 2 & 3378.65 & 0.48 & 1.44 & 3831.63 \\
\hline Geometric mean & 1541.1 & 2.302 & 3290.78 & 0.45 & 1.53 & 3643.77 \\
\hline $\mathrm{CV} \%$ & 52.5 & 39.5 & 37.8 & 24.2 & 27 & 33 \\
\hline Minimum & 478.8 & 1.5 & 1084.13 & 0.25 & 1.03 & 1818.95 \\
\hline $1^{\circ} \mathrm{Q}$ & 1010.53 & 1.75 & 2721.9 & 0.39 & 1.3 & 2834.07 \\
\hline $3^{\circ} \mathrm{Q}$ & 2346.45 & 2.63 & 4189.42 & 0.54 & 1.78 & 4433.86 \\
\hline Maximum & 4132.5 & 5 & 6522.5 & 0.67 & 2.81 & 6714.24 \\
\hline
\end{tabular}

Table 2D: Pharmacokinetic tables - Pharmacokinetic parameters. Test Product. 
Citation: Maligne GE, Feleder EC, Yerino GA, Otero AM, Roldán EJA (2018) Bioequivalence of Two Oral Dimethyl Fumarate Extended Release Capsules in Healthy Subjects: A Randomized, Open Label, Single-Dose, 2-Way Crossover Study. J Bioequiv Availab 10: 58-74. 378. doi: 10.4172/0975-0851.1000380

\begin{tabular}{|c|c|c|c|}
\hline Subject & Ln (Cmax) & $\operatorname{Ln}(A B C 0-t)$ & Ln (ABC0-inf) \\
\hline 1 & 46.27 & 35.88 & -- \\
\hline 2 & 108.6 & 105.67 & 104.85 \\
\hline 3 & 56.97 & 87.33 & 87.21 \\
\hline 4 & 132.36 & 83.89 & 83.36 \\
\hline 5 & 79.15 & 83.11 & 85.03 \\
\hline 6 & 183.46 & 111.89 & 111.86 \\
\hline 7 & 273.42 & 206.99 & -- \\
\hline 8 & 64.97 & 77.05 & 76.8 \\
\hline 9 & 75.54 & 85.99 & 86.41 \\
\hline 10 & 94.44 & 99.58 & 101.31 \\
\hline 11 & 70.62 & 120.88 & 119.6 \\
\hline 12 & 103.54 & 103.39 & 102.14 \\
\hline 13 & 158.28 & 101.73 & 102.18 \\
\hline 14 & 168.33 & 119.75 & 118.19 \\
\hline 15 & 104.51 & 71.31 & -- \\
\hline 16 & 177.27 & 144.23 & -- \\
\hline 17 & 173.79 & 148.06 & -- \\
\hline 18 & 209.79 & 122.94 & 104.9 \\
\hline 19 & 112.09 & 92.43 & -- \\
\hline 20 & 224.02 & 144.68 & 139.78 \\
\hline 22 & 73.86 & 80.4 & 80.54 \\
\hline 23 & 96.05 & 118.18 & -- \\
\hline 24 & 79.63 & 100.75 & 99.24 \\
\hline 25 & 163.42 & 92.06 & 92.7 \\
\hline 26 & 123.49 & 115.11 & 116.77 \\
\hline
\end{tabular}

Table 3: Pharmacokinetic tables - Pharmacokinetic parameters. Test/Reference quotient.

\begin{tabular}{|c|c|c|c|c|c|c|c|}
\hline Variable & Unit & Hypothesis & GL & SC & $\mathrm{CM}$ & $\mathbf{F}$ & Value $p$ \\
\hline \multirow{5}{*}{$\operatorname{Ln}($ Cmax $)$} & \multirow{5}{*}{$\mathrm{ng} / \mathrm{ml}$} & Sequence & 1 & 0.7 & 0.7 & 1.19 & 0.29 \\
\hline & & Sequence*Subject & 24.21 & 14.26 & 0.59 & 5.62 & 0 \\
\hline & & Treatment & 1 & 0.21 & 0.21 & 1.98 & 0.17 \\
\hline & & Period & 1 & 0.16 & 0.16 & 1.53 & 0.23 \\
\hline & & Error & 23 & 2.41 & 0.1 & --- & --- \\
\hline \multirow{5}{*}{$\operatorname{Ln}(A B C 0-t)$} & \multirow{5}{*}{$\mathrm{h}^{*} \mathrm{ng} / \mathrm{ml}$} & Sequence & 1 & 0.91 & 0.91 & 2.87 & 0.1 \\
\hline & & Sequence ${ }^{\star}$ Subject & 24.21 & 7.69 & 0.32 & 6.27 & 0 \\
\hline & & Treatment & 1 & 0 & 0 & 0.02 & 0.88 \\
\hline & & Period & 1 & 0.1 & 0.1 & 1.91 & 0.18 \\
\hline & & Error & 23 & 1.17 & 0.05 & --- & --- \\
\hline \multirow{5}{*}{$\operatorname{Ln}(A B C 0$-inf $)$} & \multirow{5}{*}{$\mathrm{h}^{*} \mathrm{ng} / \mathrm{ml}$} & Sequence & 1 & 0.12 & 0.12 & 0.54 & 0.47 \\
\hline & & Sequence*Subject & 22.18 & 4.8 & 0.22 & 20.34 & 0 \\
\hline & & Treatment & 1 & 0 & 0 & 0.09 & 0.77 \\
\hline & & Period & 1 & 0.05 & 0.05 & 4.6 & 0.05 \\
\hline & & Error & 16 & 0.17 & 0.01 & --- & --- \\
\hline
\end{tabular}

Table 4: Variance analysis

\begin{tabular}{|c|c|c|c|}
\hline Variable & Unit & Hypothesis & Estimator \\
\hline $\operatorname{Ln}($ Cmax $)$ & $\mathrm{ng} / \mathrm{ml}$ & CVintersubject & 0.523452 \\
\hline $\operatorname{Ln}($ Cmax $)$ & $\mathrm{ng} / \mathrm{ml}$ & CVintrasubject & 0.331502 \\
\hline $\operatorname{Ln}(A B C 0-t)$ & $\mathrm{h}^{*} \mathrm{ng} / \mathrm{ml}$ & CVintersubject & 0.37794 \\
\hline $\operatorname{Ln}(A B C 0-t)$ & $\mathrm{h}^{*} \mathrm{ng} / \mathrm{ml}$ & CVintrasubject & 0.227305 \\
\hline $\operatorname{Ln}(A B C 0$-inf $)$ & $\mathrm{h}^{*} \mathrm{ng} / \mathrm{ml}$ & CVintersubject & 0.329039 \\
\hline $\operatorname{Ln}(A B C 0$-inf $)$ & $h^{*} n g / m l$ & CVintrasubject & 0.103137 \\
\hline
\end{tabular}

Table 5: Variance components. 
Citation: Maligne GE, Feleder EC, Yerino GA, Otero AM, Roldán EJA (2018) Bioequivalence of Two Oral Dimethyl Fumarate Extended Release Capsules in Healthy Subjects: A Randomized, Open Label, Single-Dose, 2-Way Crossover Study. J Bioequiv Availab 10: 58-74. 378. doi: 10.4172/0975-0851.1000380

\begin{tabular}{|c|c|c|c|c|c|c|c|c|c|}
\hline Parameter & Unit & $\begin{array}{c}\text { MCM } \\
\text { Ref }\end{array}$ & $\begin{array}{c}\text { MCM } \\
\text { Test }\end{array}$ & Ratio [\%Ref] & $\begin{array}{l}\text { IC90\% } \\
\text { Lower }\end{array}$ & $\begin{array}{l}\text { IC90\% } \\
\text { Upper }\end{array}$ & $\begin{array}{c}\text { Prob } \\
<80.00\end{array}$ & $\begin{array}{c}\text { Prob } \\
>125.00\end{array}$ & Power \\
\hline LnCmax & $\mathrm{ng} / \mathrm{ml}$ & 7.21 & 7.34 & 113.7 & 97.27 & 132.9 & 0 & 0.15 & 0.77 \\
\hline LnABC0-t & $\mathrm{h}^{*} \mathrm{ng} / \mathrm{ml}$ & 8.09 & 8.1 & 100.97 & 90.59 & 112.54 & 0 & 0 & 0.96 \\
\hline LnABC0-inf & $\mathrm{h}^{\star} \mathrm{ng} / \mathrm{ml}$ & 8.21 & 8.2 & 98.99 & 93.29 & 105.05 & 0 & 0 & 1 \\
\hline
\end{tabular}

Table 6: Bioequivalence results.

To our knowledge, no other bioequivalence study evaluating DMF as a single dosage formulation of $240 \mathrm{mg}$ extended release capsules between a generic and brand-name product has been previously reported in the literature.

During the study process, the sensibility of the analytical method was improved, therefore the lowest limit of quantification (LLOQ) corresponding to MMF was $0,0242 \mu \mathrm{g}$, making it useful for the further monitoring of MS patients in practice. Few MS patients have been included in clinical trials, and the studies were done in other regions. Therefore, the monitoring of local patients is important being MS a condition impacted with environmental factors.

\section{Conclusion}

The point estimate of $90 \%$ CI for the log-transformed $C_{\max }$, AUC0last and AUCinf were in the range of $80-125 \%$. Type II error of the statistical test were close to the unity, meaning adequate sample size and statistical power. No statistically significant difference was found for fixed effects when ANOVA test was applied to the $\ln \mathrm{C}_{\max }$, AUC0-last and AUCinf. Both formulations were similar in terms of rate and extent of absorption. This study demonstrated that the new pharmaceutical equivalent $240 \mathrm{mg}$ DMF extended release capsules is also bioequivalent to the reference product. Then, considering that test product is pharmaceutical equivalent and bioequivalent, implies that both products are therapeutically equivalent and interchangeable (Table 6).

\section{Acknowledgment}

All authors are grateful to Dr. Carlos Feleder, FP Clinical Pharma for providing editorial support. All authors thank to Gador SA, Buenos Aires Argentina for financial support.

\section{References}

1. Dyment DA, Ebers GC, Sadovnick AD (2004) Genetics of multiple sclerosis. Lancet Neurol 3: 104-110.

2. Stephen L, Hauser J, Oksenberg R (2006) The Neurobiology of multiple sclerosis: Genes, Inflammation, and Neurodegeneration. Neuron 52: 61-76.

3. Ralf A, Linker L, Haghikia A (2016) Dimethyl fumarate in multiple sclerosis: latest developments, evidence and place in therapy. Ther Adv Chronic Dis 7: 198-207.
4. Ruggieri S, Tortorella C, Gasperini C (2014) Pharmacology and clinical efficacy of dimethyl fumarate (BG-12) for treatment of relapsing-remitting multiple sclerosis. Ther Clin Risk Manag 10: 229-239.

5. Serra A, Fox RJ (2013) Dimethyl fumarate for relapsing MS. Neurol Clin Pract 3: $249-253$.

6. Sarah L, Sheikh I, Nestorov I Russell H, O'Gorman J, et al. (2013) Tolerability and pharmacokinetics of delayed-release dimethyl fumarate administered with and without aspirin in healthy volunteers. Clinical Therapeutics 35: 1582-1594.

7. Faissner S, Gold R (2018) Efficacy and safety of the newer multiple sclerosis drugs approved since 2010. CNS Drugs 32: 269-287.

8. Tanaka M, Shimizu Y (2017) Dimethyl fumarate in multiple sclerosis. Brain Nerve 69: 1041-1046.

9. Smoot K, Spinelli KJ, Stuchiner T, Lucas L, Chen C, et al. (2017) Three-year clinical outcomes of relapsing multiple sclerosis patients treated with dimethyl fumarate in a United States community health center. Mult Scler 24: 942-950.

10. Biotti D, Ciron J (2018) First-line therapy in relapsing remitting multiple sclerosis. Rev Neurol 174: 419-428.

11. Alroughani R, Das R, Penner N, Pultz J, Taylor C, et al. (2018) Safety and efficacy of delayed-release dimethyl fumarate in pediatric patients with relapsing multiple sclerosis (FOCUS). Pediatr Neurol 83: 19-24.

12. https://www.accessdata.fda.gov/drugsatfda_docs/nda/2013/2040630rig1s000 ClinPharmR.pdf

13. http://jamanetwork.com/journals/jama/fullarticle/1760318

14. U.S. Department of Health and Human Services, Food and drug Administration Center for Drug Evaluation and Research (CDER), ICH E6 (1996) Good clinical practices: consolidated guidance.

15. U.S. Department of Health and Human Services, Food and drug Administration Center for Drug Evaluation and Research (CDER) (2003) Guidance for Industry: Bioavailability and Bioequivalence studies for orally administered drug products-general considerations.

16. Food and drug Administration (2014) Draft Guidance on Dimethyl Fumarate.

17. Marzo AL, Balant LP (1995) Bioequivalence: An updated reappraisal addressed to applications of interchangeable multi-source pharmaceutical products. Arzneimittel-forschung 45: 109-115.

18. U.S. Department of Health and Human Services, Food and drug Administration Center for Drug Evaluation and Research (CDER) (2001) Guidance for industry: Bioanalytical method validation.

19. European Agency for the Evaluation of Medicinal Products (2001) Committee for proprietary medicinal products (CPMP); Note for guidance on the investigation of Bioavailability and Bioequivalence, London. 